\title{
Repensando el Código Civil peruano de 1984 en el umbral de un nuevo milenio
}

\section{Carlos Fernández Sessarego}

1. El conocimiento del ser humano como premisa para la comprensión del derecho

\subsection{Repensando el Código Civil}

Se nos ocurre, en el umbral de un nuevo milenio y haciendo un alto en el cotidiano quehacer, repensar sobre la orientación y el mensaje del Código civil peruano de 1984. Ello, más allá de sus bondades técnicas o de sus reconocidos aportes a la codificación comparada. Como es sabido, este elogiado Código civil fue elaborado durante un largo período de tiempo que se inicia el $1^{\circ}$ de marzo de 1965 , fecha en la que se constituye lo que se conoce como la Comisión Reformadora y concluye el 24 de julio de 1984, día de su formal promulgación ${ }^{1}$.

La tarea que nos hemos propuesto, si bien es de suyo compleja, se facilita relativamente por la perspectiva que el tiempo transcurrido nos

1 La Comisión «encargada del estudio y revisión» del Código civil de 1936 conocida como "Comisión Reformadora" - se crea mediante Decreto Supremo N * 95, del primero de marzo de 1965, suscrito por el Presidente de la República Arquitecto Fernando Belaunde Terry y por quien esto escribe, Ministro de Justicia por aquel entonces. La integraron los profesores de derecho doctores José León Barandiarán, Rómulo E. Lanatta Guihem, Jorge Vega García, Jorge Eugenio Castañeda, Héctor Cornejo Chávez, Max Arias Schreiber, Ismael Bielich Flórez, por el abogado en ejercicio doctor Félix Navarro Irvine, por un delegado de la Corte Suprema y por el suscrito quien la presidiría por tener la cartera ministerial ya señalada. La Corte Suprema eligió como su representante al Vocal Supremo doctor Alberto Eguren Bresani. 
ofrece para intentar cumplir nuestro cometido. Deseamos captar el sentido, el significado y el mensaje que surgen del mencionado Código civil. Verificar si la mayoría de las instituciones que él regula responden a una posición ideológica determinada. Más allá de las incoherencias y desajustes que puedan encontrarse en su articulado y que son propios de la obra humana.

Ninguna obra humana satisface plenamente a su autor cuando éste es auténtico y humilde, cuando tiene sed de perfección. Tal vez, movidos por esta última razón, en 1992, acompañados de un numeroso y desprendido grupo de académicos, nos abocamos a revisar los aspectos técnicos del mencionado Código civil con la saludable y honesta intención no de sustituirlo por otro, sino tan sólo, de actualizarlo y perfeccionarlo ahí donde fuere necesario. Ello se explicaba, pues apenas había entrado en vigor y no contábamos ni con críticas negativas ni con una jurisprudencia que lo pusiera a prueba, sino tan sólo de enmendarlo. No había, por consiguiente y a nuestro entender, razón válida para redactar un nuevo Código civil.

Un código civil, en cuanto formal estructura normativa, prescribe y describe conductas humanas intersubjetivas valiosamente vivenciadas. Esa estructura puramente formal, desde que es de naturaleza lógica, tiene un contenido, que es vida humana en su dimensión coexistencial, valiosamente sensibilizada. La estructura formal de una norma jurídica, obviamente, no varía, es la misma en el tiempo, como el número cuatro será siempre el mismo molde formal que rellenamos con cualquier contenido real: cuatro hombres, cuatro manzanas, cuatro lápices. Es el contenido formalmente regulado el que cambia con el tiempo. La vida humana, que es libertad y es dinámica, cambia, asume situaciones nuevas, inéditas, a veces impredecibles. El derecho debe estar atento para regularlas, con sentido valioso y con toda oportunidad. Ello explica la periódica promulgación de leyes de enmiendas que cumplen la función de adecuar el contenido normativo a nuevas realidades existenciales.

Desde el día siguiente de la entrada en vigencia del Código civil de 1984 sentimos la necesidad de introducir en él enmiendas que permitieran suplir algunos vacíos advertidos o ciertas imperfecciones que conocíamos de antemano. Cabe recordar que el texto del Código fue elaborado por una comisión de juristas y revisado por otra en la que primaban los legisladores sobre los profesores de derecho. Ello explica- 
ría la existencia de tales vacíos o imperfecciones, más allá de aquellos, los menos, provenientes de sus propios autores.

Fue por ello que en el Prólogo al Tomo IV de la Exposición de Motivos y Comentarios al Código Civil de $1984^{2}$, publicada inmediatamente después de su entrada en vigencia, decíamos que el Código "pretende ser sólo un firme punto de partida para una constante y continuada reflexión, para un coherente repensamiento crítico del contenido del Código civil que asegure el ininterrumpido enriquecimiento de la ciencia jurídica que, en permanente confrontación con la realidad social valiosamente comprendida, permita introducir en él las oportunas y sagaces enmiendas que el tiempo inexorablemente exige, así como producir los desarrollos legislativos o reglamentarios que el momento histórico reclama». Y, agregábamos, «que los autores de la presente obra pretenden que las ideas enhebradas en sus páginas, que responden a las circunstancias de su época, sirvan de estímulo a las nuevas generaciones de juristas para que, al recoger su mensaje humanista, perseveren con redoblado tesón en el insosegable afán de perfección que dignifica la existencia humana ${ }^{3}$.

En los párrafos del Prólogo de la Exposición de Motivos, antes transcritos, encontramos el proyecto que nos habíamos trazado en cuanto al Código civil: «introducir en él las oportunas y sagaces enmiendas que el tiempo inexorablemente exige" luego de "una constante y continuada reflexión, para un coherente repensamiento crítico del contenido del Código Civil [...]». Ello, movidos por «un insosegable afán de perfección que dignifica la existencia humana». He aquí la clave, la explicación del esfuerzo realizado en los últimos años, no exento de contratiempos, para cumplir con esta «inexorable» e «insosegable» tarea. Por ello estamos y continuamos en la brega a fin de actualizar y perfeccionar el Código civil y para preservar, con la mayor decisión que nace de una arraigada convicción, el «mensaje humanista» del Código que, para nosotros, es su mejor logro.

Somos conscientes que el propósito humanista que inspiró a los autores del Código civil de 1984 no se cumplió a cabalidad. Existen en

2 Los aportes de la Exposición de Motivos redactados por los autores de los diversos Libros del mencionado Código fueron compilados y publicados por Delia Revoredo Marsano.

3 Código Civil. Exposición de Motivos y Comentarios al Código Civil, segunda edición, Lima, 1988, pp. 18-19. 
este cuerpo legal algunas pocas normas que lo desmienten por lo que merecen ser modificadas. A ello apunta, fundamentalmente, el intento por revisar el Código aunque imaginamos que no faltarán algunos miembros o asesores de la Comisión que pretendan lo contrario al no vivenciar los valores del humanismo que subyacen en muchos tramos de dicho cuerpo legal. Tal vez ellos responden a una trasnochada concepción individualista y patrimonialista del derecho, ayuna de ideales y valores que dignifican la vida en comunidad.

\subsection{Ser humano y derecho}

La filosofía de la existencia, de notoria gravitación en el derecho, con sus valiosos hallazgos permitió el impresionante vuelco que se experimentó, en la primera mitad del siglo XX, en la concepción del ser humano que, hasta ese momento, era considerado tan sólo como un ser racional. El «redescubrir» al ser humano como un ser con libertad, único, irrepetible, idéntico a sí mismo, facilitó comprender, con mayor diafanidad, en qué consistía la dignidad del hombre.

Los valiosos hallazgos de la filosofía de la existencia son, en cierto modo, la respuesta que en ellos suscitan, principalmente, los horrores derivados de las dos guerras mundiales que se desencadenaron en el siglo pasado así como de los nuevos y numerosos atentados contra la persona que engendra la naciente era industrial. Estos cruciales acontecimientos, más el desarrollo natural del pensamiento filosófico representado, entre otros pensadores por Kierkegaard y Niestzche, motivaron que los filósofos que habían centrado sus reflexiones en torno al ser de las cosas voltearan su mirada, presurosos y preocupados, sobre ellos mismos en un inédito afán por desentrañar, hasta donde ello fuera posible -lo que siempre fue y sigue siendo- el misterio del ser humano. Resonaba, con vigoroso eco y después de siglos, el desatendido llamado de Sócrates, que se sintetiza en el "conócete a ti mismo».

\subsection{La gravitación de la concepción humanista}

El conocimiento del hombre como ser libertad, temporal y coexistencial, que nos ofrece la filosofía de la existencia, tiene honda y amplia repercusión en el derecho. Los cardinales aportes de la filosofía de la existencia permitieron a los jusfilósofos repensar los supuestos mismos del 
derecho y, a partir de ello, superar por unidimensionales las concepciones formalista, jusnaturalista y sociologista del derecho imperantes hasta entonces en el pensamiento jurídico. Como resultado inmediato de este proceso se pudo comprender, entonces, que una concepción unitaria del derecho suponía asumirlo como el resultado de la interacción dinámica de vida humana, valores y normas jurídicas. Es decir, en virtud de esta interacción dinámica, era posible reducir a la unidad los mencionados tres objetos que hallamos en la experiencia jurídica. A ello nos referiremos más adelante.

El conocimiento de la estructura del ser humano que nos aporta la filosofía existencial brindó a los juristas la posibilidad de comprender cómo el ser humano, la persona, es el eje y el centro del derecho y, con ello, el sentido y significado de esta disciplina. Este saber nos permitió comprender que el ser humano, por su propia calidad ontológica, tiene necesidades existenciales -verdaderos derechos naturales- que el derecho objetivo debe acoger a través de derechos subjetivos incorporados a los ordenamientos jurídicos positivos. Estas exigencias existenciales deben ser tuteladas a fin que el ser humano, en cuanto libre y proyectivo, pueda realizarse como persona, pueda cumplir con su proyecto de vida.

Dichas exigencias existenciales son permanentes, no varían con el tiempo. Son inherentes a la calidad ontológica del ser humano. No dependen necesariamente del derecho objetivo. Por el contrario, los derechos naturales exigen su concreción en normas tutelares a nivel del derecho positivo.

El ser humano, en tanto libre y proyectivo, es impredecible. Los derechos de la persona no constituyen, por consiguiente, un número cerrado de derechos sino que, por el contrario, ellos se expanden en el curso de la historia conforme se hacen presentes en la vida social nuevas exigencias existenciales que requieren protección. Estas nuevas exigencias se hacen patentes, por lo general, cuando surgen inéditas amenazas o agresiones al ser humano. Los derechos de la persona se encuentran en continua expansión, en conexión con el desarrollo de la conciencia social. Por ello no son un elenco o catálogo finito, terminado.

Es así que en el siglo $\mathrm{XX}$ aparecieron dos nuevos derechos de la persona en consonancia con amenazas y agresiones que sobre ella se cernían. Nos referimos al derecho a la intimidad personal y familiar y al derecho a la identidad personal. Los extraordinarios progresos tecnológicos en el campo de las comunicaciones hicieron posible que la 
persona sintiera amenazado, cada vez más intensamente, el ámbito de su intimidad. El desarrollo tecnológico facilitó las intrusiones e injerencias arbitrarias e indebidas en la vida privada.

Son escasos los códigos civiles que contienen normas expresas protectoras de la intimidad personal. Ha sido la jurisprudencia la que, por lo general, ha tutelado este interés existencial. Para ello se ha fundado en las cláusulas generales o abiertas, como es el caso del artículo $2^{\circ}$ de la Constitución italiana de 1947 o el artículo $3^{\circ}$ de la Constitución peruana de 1993. El artículo $14^{\circ}$ del Código civil peruano de 1984 regula el derecho a la intimidad personal y familiar.

Igual sucede con el derecho a la identidad personal, el mismo que recién aparece en la década de los años ochenta del siglo pasado. Es también la jurisprudencia de algunos pocos países la que acoge este nuevo interés existencial. La persona requería ser protegida frente a todo intento de desfigurar o desnaturalizar su identidad mediante la atribución de conductas, pensamientos o creencias que no son propias de su personalidad. Es decir, se tutela la «verdad personal», el ser «yo mismo y no otro". Este novísimo derecho no se encuentra aún protegido por normas expresas, con la excepción de la Constitución del Perú de 1993, que la acoge en el inciso 1 de su artículo $2^{\circ}$, y por la reciente Constitución de la ciudad de Buenos Aires .

El más completo conocimiento del ser humano ha generado un repensamiento de la institucionalidad jurídica. Son ya numerosas aquellas figuras jurídicas que se han adecuado a la nueva concepción del ser humano que nos trajo el siglo XX. Bastaría citar, entre ellas, a la propiedad y a la responsabilidad civil, que se haya en plena y dinámica evolución hacia un derecho de daños.

El conocimiento del ser humano permite conocer su estructura y, por consiguiente, los diversos aspectos de este privilegiado ente susceptibles de ser dañados. Un caso emblemático en este orden de ideas es el referido al daño a la persona, inimaginable pocos años atrás, donde sólo se tenía en cuenta el daño emergente, el lucro cesante y, en ciertas oportunidades, el llamado daño moral. La reparación del daño a la

4 No mencionamos la Constitución de Portugal en la medida que el concepto de identidad al cual apunta es sólo el estático, es decir, el que se refiere a aquellos caracteres de la persona que no varían con el tiempo. Deja de lado la identidad dinámica, la que es propia de un ser libre que va construyendo su propia personalidad. 
persona, que aparece alrededor de los años setenta del siglo pasado, se haya en plena evolución y desarrollo.

Cabe destacar que la hondura de la influencia de la nueva concepción del ser humano en el derecho se comprueba en el hecho que, en la actualidad, el daño al proyecto de vida, que es el daño más grave que pueda sufrir la persona, ha sido recogido en la jurisprudencia argentina, en el Proyecto de Código civil de la Argentina -actualmente a nivel del Poder Legislativo-y en la jurisprudencia de la Corte Interamericana de Derechos Humanos de San José de Costa Rica. En el caso «María Elena Loayza Tamayo con el Estado Peruano" dicho tribunal alude y sustenta brillantemente el daño que se ha causado al proyecto de vida de la demandante ${ }^{5}$. Este reconocimiento internacional significa un aval del "derecho vivo" al daño al proyecto de vida.

Sólo cuando se tiene conciencia que el ser humano es una unidad psicosomática sustentada en su libertad, es posible identificar con detenimiento los alcances del daño a la persona y lograr su sistematización, hasta llegar a su expresión más radical que es el daño al proyecto de vida, es decir, aquel daño que afecta el ejercicio de la libertad. El daño a la persona puede recién ser comprendido cuando se revaloriza al ser humano, cuando se le aprehende en su peculiar calidad ontológica. La aparición de este nuevo daño comporta una revisión profunda de los criterios y técnicas para la protección del ser humano desde que no es posible aplicar, para este efecto, aquellos que se utilizan para indemnizar los daños a los objetos del mundo, a las cosas.

Mosset Iturraspe, al referirse a la inclusión del daño a la persona en el Código del 84 considera que este hecho es un aspecto sobresaliente de la evolución del derecho de daños «nacido al conjuro del artículo $1985^{\circ}$ del Código civil peruano ${ }^{6}$. El maestro argentino destaca que la materia se discutió por primera vez en el Congreso internacional celebrado en la Universidad de Lima en 1985. Ello ocurrió a raíz de una

5 Un comentario a este fallo formulado por el autor de este ensayo bajo el título de "El daño al "proyecto de vida" en una reciente sentencia de la Corte Interamericana de Derechos Humanos" puede encontrarse en la revista Diálogo con la Jurisprudencia, Editorial Gaceta Jurídica, Lima, No 12, setiembre de 1999, p. 11 y ss. También se publicó en la Argentina, bajo el mismo título, en la Revista de Responsabilidad Civil y Seguros, Editorial La Ley, Buenos Aires, No 4, agosto de 1999, p. 209 y ss.

6 Jorge Mosset Iturraspe, El valor de la vida humana, Rubinzal-Culzoni, Santa Fe, tercera edición, 1991 , p. 327. 
ponencia presentada en esa ocasión y que, de esta reunión, la figura del daño a la persona "se extendió a toda América"

El conocimiento del ser humano permitió también precisar el sentido último y la razón de ser del derecho. De un derecho creado por y para seres libres y coexistenciales desplegados en su tiempo existencial. Descubrimos, sin sombras ni tonos grises, que el derecho tiene como centro de su preocupación al ser humano, que es su sujeto. El derecho asume como misión suprema la protección de la persona, en cuanto ser libertad, para que pueda convivir con los «otros» en términos de justicia y solidaridad, a fin de realizarse integralmente, con el propósito de que cada uno de los miembros de la sociedad pueda cumplir con su proyecto de vida, cooperando al bien común.

Como se aprecia de lo dicho, se ha producido toda una revolución en el derecho a partir de la nueva concepción de lo que es el ser humano. Ello ha producido un vuelco en cuanto a los supuestos de la disciplina jurídica cuyas consecuencias empiezan a hacerse notorias a nivel de la dogmática jurídica. Esta concepción del ser humano ha obligado a un repensamiento del derecho. Ello se explica por cuanto la persona se ha convertido en el eje y centro de la disciplina jurídica. A ello ha contribuido decididamente el «redescubrimiento» de un ser humano que no sólo es racional sino que fundamentalmente, como se ha reiterado, es un ser libre, coexistencial y temporal. Esta intuición ha permitido una extraordinaria profundización y ampliación del horizonte jurídico.

\section{El individualismo como ideología y como sistema de vida}

El Código civil de 1984 se sustenta, en grandes tramos, en una concepción humanista de lo jurídico la misma que, al igual que la teoría tridimensional del derecho, se fundamenta, a su vez, en una filosofía antropológica, de raíz cristiana, que se «redescubre», reafirma y desarrolla, en el período comprendido entre las dos grandes guerras mundiales que asolaron la humanidad en el siglo XX. Nos referimos a aquel extraordinario movimiento que se conoce como el de la filosofía de la

7 Jorge Mosset Iturraspe, «El daño fundado en la dimensión del hombre en su concreta realidad", en Revista de Derecho Privado y Comunitario, $N^{\circ} 1$, RubinzalCulzoni, Santa Fe, 1991, p. 23. 
existencia. Sus aportes, en cuanto a la mostración de la estructura del ser humano en su radicalidad de ser libre y la de otros aspectos del mismo, nada o poco conocidos en precedencia, son de tal importancia y magnitud que permiten elaborar una renovada y realista concepción del derecho y de la persona ${ }^{8}$. Es a partir de esta renovada concepción - personalista que se hace posible la revisión de los fundamentos de la institucionalidad jurídica. Ella resulta una tarea insoslayable, la misma que ya comenzó a ofrecer resultados satisfactorios ${ }^{9}$.

Cuando se promulga el Código civil peruano de 1936 imperaba en el mundo una concepción formalista-positivista del derecho, fundada en una visión predominantemente de carácter individualista y patrimonialista del hombre y del mundo. Es decir, de una posición en la cual, como se ha anotado, se concebía al ser humano como un ente aislado, encerrado en sí mismo, mirando sólo su propio yo, en actitud egoísta, con prescindencia del interés ajeno y del derecho de los demás. Se trataba de un hombre desvinculado de los "otros", desconectado de la sociedad que es su hábitat natural, donde el mayor interés a proteger era el patrimonio. En síntesis, de un ser humano considerado en «abstracto", fuera de la realidad social y para quien no contaba, o contaba poco, el valor solidaridad.

De otro lado, el ser humano era valorado sólo en cuanto productor de riqueza. El homo faber era el único que interesaba proteger jurídicamente. Las consecuencias de los daños a él ocasionados eran objeto de reparación mientras que aquellos que incidían en los seres humanos desvalidos no ocupaban el centro de la atención del derecho. Así, los religiosos, las amas de casa, los artistas, los desocupados, los inválidos, los jubilados, no eran tomados en consideración cuando se trataba de resarcir los daños que hubieren injustamente sufrido. Esta óptica

8 Las obras de Heidegger, Marcel, Jaspers, Zubiri, Mounier y Sartre son medulares para poder comprender al derecho bajo una nueva óptica a partir de la vida.

9 Sobre el proceso de revisión de la institucionalidad jurídica puede verse del autor de este libro El derecho en un período de transición entre dos épocas, en Revista Jurídica del Perú, Trujillo, enero-marzo de 1996, p. 61 y ss. y "El derecho en el fin del siglo XX». Un nuevo modo de hacer derecho, en Scribas, Arequipa, Indej, No 4, 1998, p.129 y ss.

Sobre la gravitación de la filosofía de la existencia en la concepción personalista del derecho puede consultarse del autor Derecho y persona, tercera edición, p. 25 y ss. 
patrimonialista hundía sus raíces en una concepción materialista de la vida. Se protegía el haber, no el ser.

\subsection{El individualismo en el pensamiento de Mounier}

Corresponde a Mounier una correcta aproximación a lo que significa el individualismo como concepción y como sistema de vida. Para el pensador francés el individualismo "es un sistema de costumbres, de sentimientos, de ideas y de instituciones que organiza el individuo sobre esas actitudes de aislamiento y de defensa". Como lo señala el propio Mounier, el individualismo fue la ideología y la estructura dominante de la sociedad burguesa occidental entre los siglos XVIII y XIX. Se basa en la concepción de un "hombre abstracto, sin ataduras ni comunidades naturales, dios soberano en el corazón de una libertad sin dirección ni medida, que desde el primer momento vuelve hacia los otros la desconfianza, el cálculo y la reivindicación». El sistema sustentado en el individualismo crea instituciones reducidas «a asegurar la no usurpación de estos egoísmos, o su mejor rendimiento por la asociación reducida al provecho". Como se advierte, se trata de un certero y penetrante análisis del pensador francés dotado de una insuperable claridad propia del genio galo.

El lúcido filósofo francés concluye su fino análisis de lo que significa el individualismo como ideología, como sistema de vida y de organización social, al expresar que, de conformidad con su descripción, «tal es el régimen de civilización que agoniza ante nuestros ojos, uno de los más pobres que haya conocido la historia». Finaliza afirmando, con serena convicción, que el régimen individualista «es la antítesis misma del personalismo", por lo que nos advierte, con certeza, que "es su adversario más próximo" ${ }^{10}$.

La completa descripción que intenta Mounier sobre el individualismo, que cubre al menos dos centurias de esplendor y una de decadencia, contribuye a aclarar, si cabe, los alcances de esta ideología que se afirma con la Revolución Francesa y que es recogida no sólo por el Código civil de los franceses de 1804 sino por casi todos aquellos códigos civiles que lo adoptan como modelo. Si el derecho es vida, y los

10 Emmanuel Mounier, El Personalismo, Editorial EUDEBA, Buenos Aires, 1962 , p. 20. 
códigos, en gran medida, traducen el acontecer social, es explicable que los cuerpos legales civiles de casi todo el siglo XX regulen normativamente las conductas humanas intersubjetivas bajo la inspiración de la concepción individualista. El Código civil peruano de 1936, tributario de los códigos europeos de la época, no se escapa a esta influencia. Ella le viene a través del propio Código civil francés de 1804, del español de 1889, del alemán de 1900, del suizo de 1907 y del brasileño de 1916.

El individualismo, como es sabido, surge como una reacción de la burguesía frente a las estructuras feudales. El individualismo exalta al ser humano aislado y, como apunta Mounier en la primera mitad del siglo XX, se arraiga en lo económico y en lo espiritual y, como es fácilmente comprobable, "todavía produce sus estragos entre nosotros»" ${ }^{11}$.

Las expresiones de Mounier, glosadas en precedencia, son compartidas por el grupo de filósofos y pensadores que se reúnen en torno a la famosa revista francesa Esprit. Ellas son el resultado del análisis de la ideología y de los comportamientos sociales efectuado desde la perspectiva del primer tercio del presente siglo. Muchos otros trabajos han sido dedicados en el curso de dicha centuria a poner en evidencia las notas distintivas de los alcances del individualismo. Pero, entre ellos, cabe destacar, por la calidad de la fuente de la cual proviene, por su asepsia e imparcialidad, aquella realizada en el último tercio del siglo XX por su Santidad Juan Pablo II.

\subsection{El individualismo en el magisterio de Juan Pablo II}

Juan Pablo II, en la Carta Encíclica Evangelium vitae ha descrito magistralmente el sentido y alcances de la concepción individualista de la vida humana al expresar que, en la práctica, dentro de ella se niegan trágicamente los derechos humanos con la afirmación de «un concepto de libertad que exalta de modo absoluto al individuo, y no lo dispone a la solidaridad, a la plena acogida y al servicio del otro". La vigencia de un individualismo exacerbado, donde la libertad personal carece de límites, donde se olvida el deber primario y genérico de no dañar al otro, «acaba por ser la libertad de los más fuertes contra los débiles destinados a sucumbir». Su Santidad, en concordancia con lo que ve- 
nimos exponiendo, reconoce en la libertad «una esencial dimensión relacional». A la libertad propia del ser humano, en cuanto su núcleo existencial, no se le puede concebir aisladamente sino en relación con las libertades de los demás seres humanos en el seno de la comunidad.

Precisamente, esta natural coexistencialidad del ser humano que Juan Pablo II subraya, no admite una concepción meramente individualista del ser humano. La estructura del ser humano es, por ello, bidimensional: individual y social al mismo tiempo. De ahí que pueda sostenerse, sin temor a equivocarse, que el ser humano es social o no es.

En el mismo documento pontificio antes reseñado, Juan Pablo II explica que "cuando la libertad es absolutizada en clave individualista, se vacía de su contenido original y se contradice en su misma vocación y dignidad" $y$, añade, que con esta concepción individualista de la libertad "la convivencia social se deteriora profundamente", por lo que «si la promoción del propio yo se extiende en términos de autonomía absoluta, se llega inevitablemente a la negación del otro, considerado como enemigo de quien defenderse». De este modo, "la sociedad se convierte en un conjunto de individuos colocados unos junto a otros, pero sin vínculos recíprocos: cada cual quiere afirmarse independientemente de los demás, incluso haciendo prevalecer sus intereses ${ }^{12}$. Ello, como se advierte, contraría la propia naturaleza del ser humano, su simultánea estructura individual y social.

Juan Pablo II expresa que el eclipse del sentido de Dios y del hombre conduce inevitablemente a «un materialismo práctico, en el que proliferan el individualismo, el utilitarismo y el hedonismo»" ${ }^{13}$. De este modo, se caracteriza al individualismo como una de las más definidas manifestaciones de lo que se aprehende, con toda razón y verdad, como un materialismo práctico. Es decir, un pragmatismo carente de ideales y principios, ayuno de valores. Ello conduce a una civilización deshumanizada, lindante con la amoralidad.

En los tiempos que corren una concepción cerradamente ortodoxa de economía de mercado, no obstante sus reconocidas bondades para la producción de riqueza, no asegura que el hombre no resulte esclavo de la misma. La prevalencia de esta posición, ajena a los correctivos que puedan hacerse necesarios, apareja el grave riesgo, contrario al huma-

12 Juan Pablo Evangelium Vitae, Editorial Salesiana, Lima, s/f, pp. 35-36.

13 Juan Pablo II, Evangelium Vitae, p. 41. 
nismo, de colocar al ser humano al servicio de la economía y no ésta al servicio del hombre. Es por ello indispensable, de parte de gobernantes y economistas, enfocar en primer plano de atención al ser humano cuando se trata de la problemática de la economía de mercado. El mercado, por sí mismo y pese a su aporte positivo, no liberará al hombre de la miseria y, por lo tanto, el ser humano no estará en condiciones de realizarse como person ${ }^{14}$. Se requiere de una acción complementaria de parte del Estado conducente a impedir las irregularidades que puedan provenir de una economía de mercado ciega a las necesidades del ser humano.

El pensamiento del filósofo francés Emmanuel Mounier y el del conductor de la Iglesia Católica, Juan Pablo II, a los que en este orden nos hemos referido, es verificado y complementado por diversos filósofos, pensadores, jusfilósofos y destacados juristas contemporáneos que reaccionan contra el sistema de vida impuesto por el individualismo. Citaremos, en el curso de las páginas que siguen, el pensamiento de algunos de ellos entre una multiplicidad de autores que se refieren al tema.

Así, como muy bien lo percibe el jurista uruguayo Gustavo Ordoqui, el individualismo trasciende al derecho, lo impregna de sus principios, lo marca y define en cierto tramo de la historia. Es por ello que el autor sostiene con razón que «el individualismo, por error, tiende a presentar los derechos de la persona aislados de su contexto, como fuera de la natural intersubjetividad que es propia de la experiencia jurídica». De ahí que para el individualismo, según Ordoqui, «los derechos subjetivos son absolutos" y ello "porque se pierde la dimensión social", sin tenerse en cuenta que "el yo es indesligable de los otros» ${ }^{15}$. El error radical del individualismo reside, precisamente y como lo anota Ordoqui, en considerar al ser humano en abstracto, desvinculado de los demás hombres, con quienes necesariamente tiene que coexistir en sociedad. La dimensión social del hombre, su estructura ontológica coexistencial, no puede ser ignorada.

14 Santo Tomás dijo en su momento que para iniciarse en la vida de la virtud se requería de un mínimo de bienestar material.

15 Gustavo Ordoqui Castilla, "Pautas y Criterios para la avaluación judicial del daño a la persona", en Los diez años del Código Civil peruano: balance y perspectivas, Tomo II, p. 413. 


\section{Individualismo y derecho}

\subsection{La histórica presencia del individualismo en el derecho}

La visión del ser humano centrada puramente en una concepción individualista tuvo, y sigue teniendo en grandes tramos, una dominante presencia en el derecho en cuanto regulador de vida humana ${ }^{16}$. El derecho, no lo podemos olvidar, es creado por el hombre, por lo que es un producto cultural. El derecho, en este sentido, es primariamente vida humana viviente. De ahí que todo lo que está en la vida se halla en el derecho, dentro o fuera de su estructura fomal-normativa. Lo jurídico recoge el sentido de una cultura, de una manera de pensar y de vivir. Los seres humanos, explicablemente y en su inmensa mayoría, son tributarios de la ideología de su tiempo. Los códigos, a través de sus normas, que son pensamiento, congelan una determinada cultura, una cierta visión del mundo y del hombre. Por ello, como muy bien lo señalara el eminente comparatista René David, el derecho, los códigos, constituyen un medio idóneo para conocer el modo de vida y el estilo de pensamiento de un determinado grupo humano en cierto tramo de la historia.

De ahí que el sistema individualista de vida se halle visceralmente enclavado en el derecho de los siglos XVIII y XIX y se proyecta hasta el siglo XX. Su influencia está presente en el pensamiento de los juristas, gravita permanentemente en el proceso de codificación, inspira las resoluciones judiciales, alienta la regulación de las instituciones jurídicas. Su arraigo es masivo, las adhesiones con que cuenta siguen aún siendo numerosas en los días que corren. Es difícil oponer la solidaridad al egoísmo individualista, no es fácil hacer prevalecer la justicia ante la irritante injusticia ${ }^{17}$.

16 Sobre la tensión entre el individualismo y el comunitarismo ver Lino RodríguezArias, Bustamante, Del derecho liberal al derecho comunitario, Editorial Temis, Bogotá, 1995.

17 Sobre la influencia del individualismo en su versión neoliberal puede consultarse de autores varios el libro Neoliberalismo y desarrollo humano, editado por el Instituto de Ética y Desarrollo de la Escuela Superior Antonio Ruiz Montoya, Lima, 1998. 


\subsection{Un caso emblemático: la noción de "derecho subjetivo»}

Bastaría citar algunos cuantos notorios casos de individualismo jurídico -tanto por la trascendencia de lo dicho como por la calidad de los juristas que lo dicen-, para comprobar la gravitación del individualismo en el pensamiento y en la construcción de las instituciones jurídicas que hemos heredado. Uno de estos casos, emblemático por excelencia, es el referido a la tradicional y difundida noción de «derecho subjetivo». Autores exponentes de su tiempo, de la categoría de un Windscheid o de un Ihering, formularon una teoría en torno a la significación jurídica del derecho subjetivo. Su concepción respondía a los dictados del individualismo dominante en el momento histórico que les tocó vivir. Su pensamiento en esta materia, como en otras muchas, fue recogido, sin excepción, por los juristas de su tiempo y sus ecos llegan hasta nuestros días.

En el Perú de los años cuarenta y cincuenta del siglo XX, período de nuestra formación universitaria, los grandes maestros peruanos exponían dogmáticamente la noción de derecho subjetivo forjada por ambos, con los matices diferenciales que son conocidos. No existía otra alternativa en el pensamiento de la época. Continuaron haciéndolo por muchos años más. Con gran dificultad, su pensamiento, al influjo de la corriente de pensamiento personalista, va siendo paulatinamente sustituido por una moderna concepción sustentada en una distinta antropología filosófica, en correspondencia con lo que acontece en el devenir de la vida social. Teoría y realidad, dentro de esta nueva perspectiva, guardan estrecha armonía.

Inspirado en el individualismo jurídico, Windscheid definió al «derecho subjetivo" como «un poder de la voluntad» atribuido por la norma al titular del mismo ${ }^{18}$. Según este clásico autor «los derechos existen en cuanto el ordenamiento jurídico ha declarado decisivo para la actuación de un precepto emanado de él, la voluntad de una persona». Ihering, bajo la misma influencia ${ }^{19}$, lo considera como «la tutela jurídica de un interés del individuo». Estas clásicas y difundidas definiciones, que comúnmente imperan sin mayor análisis crítico hasta nuestros días, no

18 Windscheid, Diritto delle pandette, Tomo I, Torino, 1925, p. 144.

19 Rudolf von Ihering, El espíritu del derecho romano en las diversas fases de su desarrollo, T.IV, Madrid, de Bayllye Bailliere, 1905, p. 364 y ss. 
prestan ninguna atención al derecho de los demás en el ámbito social sino tan sólo a «la omnímoda voluntad o al exclusivo interés del individuon.

Ambas teorías están centradas en la egoísta voluntad o el interés del individuo, aislado de su comunidad, desvinculado de los demás seres olvidando que con ellos, y gracias a ellos, hace su vida, construye su futuro, se proyecta y lo preserva. Ambas posiciones prescinden del interés de los «otros», como si sólo cada uno de nosotros existiera sobre la faz de la tierra. Dentro de esta tendencia era perfectamente lógico que los derechos subjetivos se estimasen absolutos, por lo que en su ejercicio "regular" podíase lesionar impunemente el derecho ajeno sin responsabilidad alguna para el agente del daño. No se legislaba aún sobre el abuso del derecho, que es una institución contemporánea por la cual se protege el interés existencial de los demás en ausencia de un expreso derecho subjetivo que cumpla con tal finalidad.

\subsection{La concepción predominantemente patrimonialista del derecho}

El exacerbado individualismo reinante en el siglo XIX y en la primera mitad del siglo XX que, como se sabe, es expresión de un momento histórico, condujo, como era natural, a una concepción predominantemente patrimonialista del derecho. Lo que interesaba primordialmente al legislador, hombre de su tiempo, era la protección normativa de la propiedad individual, privada, absoluta y exclusiva del individuo. El derecho de propiedad, dentro de la soberbia individualista, fue considerado como un derecho calificado de «absoluto, sagrado e inviolable». Así aparece diseñado en el Código de Napoléon. Bien sabemos en la actualidad, gracias a la nueva concepción del hombre, que no existen derechos absolutos, que todo derecho conlleva en su seno el deber genérico que es el de no dañar al «otro» en el ejercicio de un derecho subjetivo.

De otro lado, lo único "sagrado» es el ser humano que, según la teología católica es templo del espíritu santo. Finalmente, sabemos también que no existen derechos «inviolables», que todo derecho puede ser transgredido desde que el ser humano es libre de cumplir con su deber o de incumplirlo. La inviolabilidad carece de sustento técnico. Es, tan sólo, una aspiración ética.

La propiedad se erigió en el centro de atención de los sistemas jurídicos positivos. Baste recordar, como penosa anécdota, que en las 
Constituciones peruanas de 1979 y 1993 se sigue aún considerando al derecho de propiedad como un derecho «inviolablem, situación que, paradójicamente, no se menciona tratándose de los derechos fundamentales de la persona, como son los derechos a su vida o a su liber$\operatorname{tad}^{20}$. Se trata, sin duda, de un rezago, tal vez subconsciente en algunos casos, de una concepción meramente individualista de la propiedad.

El individualismo, llevado a sus extremos de predominio absoluto del egoísmo sobre la solidaridad, genera un modelo de sociedad "caracterizada por el predominio de lo económico sobre lo político y lo jurídico, por una parte, y la exaltación de la fuerza y la inclinación a los métodos de violencia, por otra». Es este el sintético panorama que esboza Rodríguez-Arias Bustamante, que tiene su correlato en la realidad de ciertas sociedades contemporáneas. Observamos como, en ciertos ordenamientos jurídicos nacionales, el elemento dominante en la concepción del hombre y del mundo es lo material o patrimonial sobre lo espiritual. Como sostiene el autor, ello es «verdaderamente lamentable, como el empleo de la fuerza, cada vez más acentuada, lo cual amenaza por destruir las garantías de la seguridad a que aspiran todos los seres humanos». Ello conduce, en última instancia, a la destrucción o, cuando menos, a la peligrosa atenuación del Estado de Derecho ${ }^{21} \cdot{ }^{\circ}$ No es ésta, de alguna manera y en cierta medida la experiencia del Perú de la última década del siglo XX? ¿ No es éste acaso el «materialismo pragmático" al que tan claramente alude Juan Pablo II en la Encíclica

20 Nos referimos a los artículos $125^{\circ}$ de la Constitución de 1979 y $70^{\circ}$ de la Constitución de 1993. Este último numeral prescribe que: «el derecho de propiedad es inviolable». Aparte del singular hecho que los constituyentes de 1979 y 1993 reservaron el calificativo para aplicarlo al caso del derecho de propiedad, es dable señalar que, en principio y en cuanto al ser humano es libre, es capaz de cumplir con su propio deber o incumplir con él, violando en este caso la prescripción normativa. Es decir, que señalar que un derecho es "inviolable" significa tan sólo una aspiración ético-axiológica, por lo que no condice con una buen técnica legislativa. Desde nuestro punto de vista, esta situación representa un rezago de una trasnochada visión exarcebadamente individualista y patrimonialista del derecho, donde el centro y eje del mismo no se halla en la persona humana sino en la propiedad. Es este el único interés existencial que para el constituyente merecería ser uinviolable», con prescindencia o anteponiéndose a los derechos a la vida o la libertad, por ejemplo.

21 Lino Rodríguez-Arias Bustamante, Del derecho liberal al derecho comunitario, pp. 23-24. 
Evangelium Vitae? ${ }^{22}$. ¿No será éste, acaso, la causa de la profunda crisis moral de la sociedad contemporánea a la que la generalidad de las personas identifica con diversos tipos o modalidades de "corrupción", algunos de las cuales conocemos con estupor a través de las informaciones que nos ofrecen los medios de comunicación social?

El individualismo extremo conduce a un pragmatismo donde lo límite ya no es la inmoralidad sino la amoralidad. Los que profesan esta visión del mundo y del hombre terminan por colocar en el ápice su escala de valores a su conveniencia, a la utilidad, en vez de los cimeros valores del amor, la solidaridad y la justicia que otorgan sentido y dignifican la vida humana. Se trata de una grave deshumanización de la convivencia humana que hay que combatir y desterrar hasta donde ello es humanamente posible.

\subsection{El lento destierro de la concepción individualista}

Felizmente, no obstante su secular arraigo y su persistente presencia en la vida comunitaria, la posición eminentemente individualista-patrimonialista va siendo lentamente desterrada de la normatividad contemporánea, pese al renacer de un extremo y gélido neoliberalismo económico en el último tercio del siglo XX. Como comprobación de este proceso de destierro del individualismo extremo cabe destacar el hecho de que en Alemania, una enmienda constitucional del 19 de marzo de 1956, enuncia en su primer artículo que "la dignidad del hombre es sagrada y constituye deber de todas las autoridades del Estado su respeto y protección». Esta declaración representa, entre muchas otras similares producidas en otras latitudes, una creciente toma de conciencia del significado y primado de los derechos fundamentales derivados de la dignidad del ser humano y, consiguientemente, una paulatina reacción contra el "materialismo pragmático" que nos agobia e impide o limita el normal y equilibrado desarrollo de la personalidad humana.

Bajo la inspiración de la filosofía de la existencia y de la Declaración Universal de los Derechos Humanos, que en gran medida la concreta normativamente, los códigos civiles de Bolivia de 1976 y el reciente código de Quebec, entre otros, siguen una nueva directiva de principios. En el artículo $3^{\circ}$ del primero de los citados códigos civiles se 
declara que "los derechos de la personalidad son inviolables", posición que difiere de aquella lamentablemente adoptada por nuestros constituyentes de 1979 y de 1993 para quienes, como se ha apuntado, sólo el derecho de propiedad sería inviolable.

El artículo $10^{\circ}$ del reciente Código civil del Quebec enuncia que «la persona humana es inviolable». Al mencionar a la persona humana, en cuanto titular de todos sus derechos naturales, resultan por consiguiente inviolables todos aquellos que la protegen dentro del respectivo ordenamiento jurídico. En este mismo sentido, el artículo $1^{\circ}$ de la derogada Constitución peruana de 1979 proclamaba que la persona era el bien supremo del Estado y de la sociedad aunque, contradictoriamente y como está dicho, reservaba el calificativo de «inviolable» para caracterizar el derecho de propiedad. Es decir, en otros términos, lo que la Constitución estableció es que el ser humano es un fin en sí mismo, mientras que el patrimonio es tan sólo un indispensable instrumento a su servicio.

El artículo $2^{\circ}$ de la Constitución italiana de 1947 proclama que «la República reconoce y garantiza los derechos inviolables del hombre, ya sea como sujeto singular o en las formaciones sociales, donde desarrolla su personalidad». Este artículo constitucional, que funciona como cláusula abierta o en blanco, ha permitido a los jueces italianos proteger todos los derechos naturales o intereses existenciales de la persona, estén o no tutelados por norma expresa del ordenamiento jurídico positivo. De otra manera no se explica que la jurisprudencia de la península haya recogido y protegido simples intereses existenciales como son la intimidad o la identidad, los que no cuentan con norma expresa que los tutele dentro de dicho ordenamiento jurídico. Los jueces se han fundado en dicha norma constitucional para acogerlos, sustentándose en la libertad y la dignidad del ser humano y la consiguiente inviolabilidad de sus derechos naturales.

Como se aprecia, en todas las Constituciones antes mencionadas y en otros dispositivos citados, el término de «inviolable» se reserva, como debe ser, para la vida humana, para el ser humano, y no para la propiedad como indebidamente aún lo sigue haciendo la Constitución de 1993 siguiendo de este modo, acríticamente, las huellas de su antecesora la Constitución de 1979. Esperemos que este grueso error -o involuntario e inadvertido desliz- no se repita en la próxima Carta Magna. Y decimos desliz, porque de la lectura de su bello Preámbulo se 
infiere su inspiración humanista desde que se reconoce expresamente "la primacía de la persona humana y en que todos los hombres, iguales en dignidad, tienen derechos de validez universal, anteriores y superiores al Estado». Esta declaración, acorde con la naturaleza del ser humano, justifican nuestra apreciación.

Un paso adelante de singular importancia en el reconocimiento y gravitación de la concepción personalista fue dado con ocasión de aprobarse un 10 de diciembre de 1948 la Declaración Universal de los Derechos Humanos. Este valioso instrumento, que acaba de cumplir cincuenta años de vigencia, sirvió de inspiración a las constituciones y a los códigos civiles promulgados en la segunda mitad del siglo XX que, después de un prolongado olvido y preterición de parte del derecho positivo, reconocen y protegen los derechos fundamentales de la persona.

Lamentablemente, y bien lo sabemos por propia experiencia, los gobiernos autoritarios o dictatoriales suelen desconocer en la práctica, con mayor o menor intensidad, los derechos fundamentales del ser humano violándolos, a menudo, sistemáticamente. A los gobernantes más o menos autoritarios no les interesa la protección del ser humano. Sus pragmáticos antivalores son su propia conveniencia para mantenerse en el poder, sofocando cualquier intento de rebeldía o de protesta. No obstante estas duras experiencias cíclicas negativas, contrarias a la dignidad del ser humano que viven algunos países -entre ellos, el nuestro-, será seguramente contrarrestada en un próximo futuro a través de un proceso de globalización jurídica que, en la huella de aquella de índole económico-financiera, empieza a percibirse en el mundo. Este será, sin duda, un factor de importancia para frenar, mitigar o impedir tales actos de barbarie que aún temporalmente asolan a la humanidad. En este sentido es lamentable que el Perú, junto con Uruguay, sean los únicos países latinoamericanos que aún no han suscrito el Tratado de Roma de creación del Tribunal Penal Internacional, el que perseguirá a los delincuentes que, en cualquier latitud, cometan crímenes contra el ser humano, con prescindencia de su raza, creencias o ubicación geográfica. Se trata, sin duda, de un avance extraordinario en el sentido de protección del ser humano. 


\section{La concepción individualista-patrimonialista y el Código civil de 1936}

Es útil mostrar cómo el Código civil de 1936, tributario de su tiempo y de las fuentes de las que se nutrieron sus autores, tenía como centro de su interés la protección del patrimonio, con desmedro de la tutela del ser humano. Como todos los códigos civiles de su tiempo apenas tenían unas cuantas normas destinadas a la protección del ser humano. En el Código civil de 1936 sólo se mencionaban los derechos al nombre y al domicilio. No se tutelaban los derechos fundamentales a la vida, la libertad, la integridad psicosomática, el honor, la intimidad, entre otros.

\subsection{Contexto histórico-ideológico en el que se elabora el Código de 1936}

La Constitución peruana de 1933, que regía en el período de nuestra formación jurídica, no tutelaba los derechos de la persona. Su exclusiva preocupación, como aquella de la mayoría de las cartas magnas que la antecedieron en el tiempo, era básicamente diseñar la institucionalidad del Estado y la regulación las relaciones entre éste y los ciudadanos. Dicha Constitución se constituiría en el fundamento del Código civil de 1936.

Es bajo la inspiración de una filosofía individualista, heredada del Código civil de los franceses de 1804, que se redacta el Código civil de 1936. Ello explica, por ejemplo que, entre otras razones, en el Libro dedicado al Derecho de las Personas sólo se consideraran dignos de tutela jurídica tan sólo el nombre y el domicilio, con absoluto desconocimiento de los derechos fundamentales a la vida, a la libertad, a la identidad, a la integridad psicosomática, al honor o a la intimidad, para citar sólo algunos de los más importantes derechos del ser humano sustentados en su propia dignidad de ser libre y coexistencial. La pobreza del Libro Primero del Código civil de 1936 en el tratamiento de los derechos fundamentales de la persona, como ha sido resaltada por varios de sus comentaristas, era notoria. Se hacía indispensable, por consiguiente, reestructurar íntegramente dicho Libro Primero a partir de una visión personalista del derecho. Dicho Libro había devenido obsoleto. No era posible enmienda alguna. Había que reestructurarlo desde su misma base ideológica. 
La concepción individualista, como se ha anotado, se halla estrechamente unida a la predominante presencia de una visión patrimonialista de la vida y, por ende, del derecho. La acumulación de riqueza y su casi nula distribución, la producción de rentas, la protección de lo habido, son el natural y explicable corolario del individualismo que sólo tiene en consideración la satisfacción de las necesidades del individuo en soledad. Lo más importante, lo decisivo, dentro de la mentalidad individualista es el «haber» en desmedro del «ser». Dentro de esta concepción marcada por el egoísmo, más importante resulta ser la tutela del patrimonio que la protección del ser humano considerado en sí mismo.

La concepción individualista-patrimonialista se refleja en la construcción de casi todas instituciones jurídicas plasmadas bajo su inspiración ideológica. La propiedad, en su manifestación normativa, es un derecho «absoluto, sagrado e inviolable». Ninguno de estos calificativos es aplicado, sin embargo, a la vida humana. Se reservan, como está dicho, tan sólo para calificar "jurídicamente» al patrimonio. Esta es la cosmovisión dominante en la época en que se formula el Código civil de 1936 y de la que, explicablemente, no lograron desprenderse, totalmente, los constituyentes de 1979 y de 1993.

Tan intensa y vasta fue $-y$ en alguna medida lo sigue siendo- la presencia del individualismo-patrimonialista que esta concepción se trasunta en todas las disciplinas jurídicas, se aloja en el corazón de todas las instituciones jurídicas. No sólo la propiedad resulta «inviolable», como se ha señalado sino que, por ejemplo, en el área de la responsabilidad civil lo que se protege es al homo faber, al ser humano sólo en cuanto productor de rentas. Para la jurisprudencia comparada, hasta hace muy pocos años, carecía por ello de sentido proteger al ser humano, considerado en sí mismo, si es que él no generaba riqueza. El valor que tenía el ser humano para el derecho se hallaba en función de la riqueza que producía. Su protección jurídica se medía en atención a sus haberes. No interesaba, por consiguiente, el ser humano en cuanto tal. Por ello, muchos seres humanos no productores de riqueza quedaban marginados de la tutela del derecho ante los daños de que podían ser víctimas. Era el caso, entre otros y como lo hemos señalado, de las amas de casa, de los niños, de los ancianos, de los desocupados, de los discapacitados, de los jubilados, de los sacerdotes, de los que, en general, dedican su vida, con total desprendimiento, al servicio de los demás. 
La gravitación del individualismo, si bien ha disminuido en intensidad en años recientes, no ha desaparecido totalmente de la escena jurídica. Ello es reflejo de lo que acaece en el mundo en que vivimos. Su presencia aún se advierte bajo diversas manifestaciones. Ella es avivada desde la vertiente económica por un capitalismo salvaje, por un neoliberalismo extremo y eviscerado que no admite regulación alguna de protección al débil, por una teoría del costo-beneficio que pretende arrasar con los valores supremos vivenciados en las relaciones jurídicas, como son la justicia o la solidaridad, para ser sustituidos por otros, que si bien son importantes, resultan de menor jerarquía axiológica, como es el caso de la utilidad o la conveniencia.

\subsection{Período de transición entre dos épocas}

Pese a la situación antes referida, se observa que en ciertos sectores del derecho, en concordancia con la vida, se está desplazando, no sin fatiga y esfuerzo, la influencia absoluta del individualismo-patrimonialista. Ello nos hace intuir y pensar, como lo hemos reiteradamente expresado en otras sedes que, no obstante los rebrotes individualistas que se advierten en la actualidad, nos encontramos en un período de transición entre dos épocas. Una transición que tiene como meta un futuro -no sabemos cuán lejano esté- signado por el humanismo. Hemos dedicado algunas páginas en otras sedes al análisis de este fenómeno ${ }^{23}$.

Prueba de este proceso de cruenta transición ideológica, en el cual se advierte que en ciertas áreas del derecho la influencia individualista se halla en retirada, es el notorio viraje producido en cuanto a la noción de "derecho subjetivo" que en su tiempo, como es sabido, preconizaran Windscheid y Ihering. De ser un derecho absoluto, un indiscriminado e ilimitado poder de voluntad individual, va transformándose en lo que se ha dado en llamar «situación jurídica subjetiva». Dentro de los alcances de este concepto, el derecho subjetivo pierde su falsa calidad de derecho "absoluto", con que lo nimbó el individualismo, para ceder paso a una concepción concorde con la realidad de la vida social y con los hallazgos de una contemporánea antropología filosófica.

23 Ver Carlos Fernández Sessarego, «El derecho en un período de transición entre dos épocas", Revista Jurídica del Perú, Editora Normas Legales, Trujillo, enero-marzo de 1996. 
El «derecho subjetivo» se presenta dentro de esta nueva óptica acompañado siempre de un correspondiente deber. Como las dos caras de una moneda, derecho y deber son inseparables. No hay derecho que no contenga ínsito en su seno un determinado deber frente a los demás, como tampoco es imaginable un deber que no signifique un cierto derecho. El deber aludido puede ser genérico, es decir, presente en toda la normatividad jurídica $\mathrm{y}$, además, propio de cada figura del derecho. El deber genérico, que se halla presente y actuante en todos los derechos subjetivos, es el de no dañar. Ello supone que en el ejercicio de un derecho no se puede impunemente causar un perjuicio a otro. Lo dicho significa que no existe un derecho subjetivo absoluto en tanto está siempre inherentemente limitado, al menos, por el genérico deber de «no dañar» ${ }^{24}$.

En el artículo $19^{\circ}$ del Código civil peruano de 1984 encontramos un caso en el cual se señala expresamente que el nombre es «un derecho y un deber». En esta situación el deber genérico es no dañar a otro a través de un uso indebido del nombre. El deber específico, propio de la figura, es el de no cambiar de nombre. Ello, en cuanto el nombre es uno de los signos distintivos de la identidad del sujeto, con el cual general y normalmente, se le individualiza en sociedad. Claro está que este deber de no cambiar de nombre reconoce algunas excepciones por todos conocidas, como es el caso de las homonimias intolerables, los nombre ridículos, extravagantes, lesivos al honor, entre otros casos que el juez deberá apreciar.

Otro caso en el que se hace patente la transición entre dos épocas, una dominada por el individualismo-patrimonialista y la otra bajo el signo de un humanismo solidario, es el que se observa tratándose de la tutela del ser humano. Observamos como en las más recientes Constituciones, inspiradas en la Declaración Universal de los Derechos Humanos, se hace referencia a los derechos fundamentales del ser humano. Esta actitud se traslada a ciertos códigos recientes. Tanto en unas como en otros se incluyen cláusulas generales, abiertas o en blanco, de protección preventiva, unitaria e integral de la persona. Ello significa, por consiguiente que en lo que atańe a los derechos de la persona no existe un

24 Una mayor información sobre el tema concerniente a la «situación jurídica subjetiva" se puede encontrar en Carlos Fernández Sessarego, Abuso del derecho, Astrea, Buenos Aires, 1992 p. 54 y ss. 
número cerrado de derechos. Es decir, que no es necesario que un derecho natural, que una exigencia existencial sustentada en la dignidad del ser humano, requiera de norma expresa que lo tutele para que sea amparada por el juez. En esta hipótesis el juez fundamenta su fallo, como se ha señalado, en la facultad que le concede el ordenamiento a través de las cláusulas generales y abierta de protección del ser humano.

Ni la Constitución peruana de 1933, ni el Código civil de 1936, como no podía ser de otra manera, incorporaron dentro de sus respectivos articulados una cláusula general de tutela preventiva, integral y unitaria de la persona. Tampoco aludieron a la protección de cualquier interés existencial o derecho natural derivado de la dignidad misma de la persona, aunque no estuviere expresamente considerado por una determinada norma jurídica. Esta omisión resultaba muy grave en la medida que, según los postulados del positivismo jurídico que inspiraron al codificador de 1936, sólo era de aplicación por el juez aquello taxativamente previsto por la ley. No habíase aún configurado un derecho genérico de tutela de la persona como es el que aparece en el artículo $4^{\circ}$ de la Constitución peruana de 1979 y en el artículo $5^{\circ}$ del Código civil de 1984 , lo que significa un evidente y positivo desarrollo en materia de protección preventiva, unitaria e integral del ser humano ${ }^{25}$.

En el artículo $5^{\circ}$ del Código civil de 1984 , en concordancia con lo dispuesto en su momento en la Constitución de 1979, incluye también una cláusula abierta pues, al lado de la protección expresa de los derechos fundamentales de la persona a la vida, la libertad, a la integridad psicosomática, al honor, prescribe que gozan también de la misma protección los «demás inherentes a la persona humana».

Lo expresado en el párrafo anterior marca la abismal diferencia conceptual y normativa entre la magra protección a la persona dispensada por el Código civil de 1936 y aquella amplia tutela preventiva, unitaria e integral brindada por el Código civil de 1984. El salto de calidad,

25 Los artículos $4^{\circ}$ de la Constitución de 1979 y $3^{\circ}$ de la de 1993 contienen una ejemplar cláusula general redactada en los siguiente términos: «La enumeración de los derechos reconocidos en este capítulo no excluye los demás que la Constitución garantiza, ni otros de naturaleza análoga o que derivan de la dignidad del hombre, del principio de soberanía del pueblo, del Estado social y democrático de derecho y de la forma republicana de gobierno". El art. 5 del Código civil peruano de 1984 recoge este principio cuando, al referirse a algunos derechos fundamentales de la persona, extiende la protección jurídica a "los demás inherentes a la persona humana». 
como ha sido puesto en evidencia por los comentaristas del Código civil de 1984, es por demás elocuente.

\section{Alcances de la concepción personalista}

\subsection{Origen y significado del personalismo}

El personalismo es una elaborada expresión del humanismo. Es, en síntesis, un humanismo. Por ello suelen utilizarse ambos términos como sinónimos. En cierta medida, lo son. En las líneas que siguen se hará referencia a algunos matices propios del personalismo.

Como lo señala Mounier en su bello y denso libro titulado El Personalismo, la palabra "personalismo" encuentra su origen en los primeros años del siglo XX. La empleó Renouvier por primera vez en Francia en 1903 para calificar su filosofía. Luego cayó en desuso en este país para ser posteriormente retomada en Estados Unidos por algunos seguidores de Walt Whitman. Reaparece en Francia en 1930 para designar las primeras indagaciones publicadas en torno a este concepto en la revista Esprit. Es utilizada por algunos grupos próximos a esta revista, a propósito de la crisis política y espiritual que estallaba en Europa después de la primera guerra mundial de 1914-1919. Como apunta Renouvier, en 1947 el conocido Diccionario Filosófico de Lalande le otorga carta de ciudadanía en su quinta edición mientras que, contra el uso corriente del vocablo, el diccionario Larrouse le otorga al término "personalismo" el significado de egocentrismo. Como observa Mounier, la palabra personalismo «sigue una marcha indecisa y ramificada: la de una inspiración que se busca y ensaya sus vías" ${ }^{26}$. En esto último reside la amplitud y grandeza del personalismo ${ }^{27}$.

No obstante lo expresado por Mounier, y como él mismo lo advierte, lo que se llama personalismo «no es, de ningún modo, una novedad». El personalismo entronca en una larga tradición. En una tradi-

26 Emmanuel Mounier, El Personalismo, p. 5.

27 Según otra versión, el personalismo «surgió como reacción de unos pensadores cristianos ante la crisis mundial del año 1929, que intenta superar al liberalismo y al socialismo, despojándolos de sus excesos extremistas: el sentido del individuo o la colectividad" Ver Lino Rodríguez-Arias Bustamante, Del derecho liberal al derecho comunitario, p.4. 
ción que se proyecta vigorosamente al futuro. El vocablo pudo haber sido acuñado a comienzos del siglo XX pero la concepción que él revela es de larga data histórica.

Según el citado filósofo francés, el personalismo no es un sistema cerrado de pensamiento. El personalismo es una filosofía, es una actitud. Como bien lo expresa Mounier, el personalismo «no rehuye la sistematización, pues el orden es indispensable en los pensamientos: conceptos, lógica, esquemas de unificación no sólo son útiles para fijar y comunicar un pensamiento que sin ellos se disolvería en intuiciones opacas y solitarias; sirven para sondear esas intuiciones en sus profundidades». Son por ello, «instrumentos de descubrimiento al mismo tiempo que de exposición". Como postula Mounier, por cuanto determina estructuras, "el personalismo es una filosofía y no solamente una actitud $n^{28}$. Actitud y filosofía centradas sobre el valor de la persona humana.

\subsection{La idea central del personalismo}

La idea central de la filosofía personalista es la existencia de personas libres y, en tanto tal, creadoras. El ser humano deja de ser, solamente, un ente racional. Su núcleo existencial es la libertad. La libertad es constitutiva de la existencia creada. Por ello la persona es estimativa, estructuralmente dispuesta a valorar, lo que le permite proyectar. El ser humano es, así, estimativo. Pero, por ser libre y temporal, es también proyectivo. Por ser libre, la persona es dinámica e impredecible. Precisamente, y como anota Mounier, por ser impredecible ella «disloca toda posibilidad de sistematización definitiva ${ }^{29}$.

La libertad y la persona son indefinibles. Como lo recuerda el propio Mounier, sólo se pueden definir los objetos exteriores al ser humano, los objetos que tenemos ante la mirada. La persona no es un objeto. El ser humano es el sujeto que conoce, que enfrenta a los objetos del universo. Como bien lo describe el autor, «la persona no es el más maravilloso objeto del mundo, un objeto al que conoceríamos desde fuera, como a los demás». Es, por el contrario, «la única realidad que podemos conocer y que al mismo tiempo hacemos desde dentro" ${ }^{30}$. La

28 Emmanuel Mounier, El Personalismo, p. 5.

29 Emmanuel Mounier, Op. cit., p. 6.

30 Mounier, Emmanuel, Op. cit., pp. 6-7. 
realidad humana, como apunta Julián Marías, es la única que conocemos directamente ${ }^{31}$.

Tratar a la persona como un sujeto, como a un ser presente y no como a un objeto, supone, como apunta Mounier ${ }^{32}$, «reconocer que no se puede definirlo, clasificarlo, que es inagotable, que está henchido de esperanzas, y que sólo él dispone de ellas: es concederle crédito". El ser humano es un universo de posibilidades, de iniciativas, de opciones para realizar su vida. Es un ser complejo, de una riqueza extraordinaria del cual poco sabemos a pesar de los valiosos hallazgos de la filosofía de la existencia.

\subsection{La aprehensión del ser humano como libertad}

Es cierto, sin embargo, que podemos aprehender desde el exterior ciertos aspectos de cada ser humano. Observamos su contorno físico, sus características, los rasgos de su personalidad. Podemos analizar su sangre, someterlo a pruebas de laboratorio, determinar sus enfermedades. Es decir, lo podemos tratar como a un objeto del saber fisiológico. Podemos también conocer muchos de sus atributos, como los atinentes a su creencia religiosa, sus convicciones políticas, su nacionalidad, su ocupación. Es decir, podemos aprehender desde el exterior muchas facetas de este ser impredecible que es el ser humano, pero nunca podremos conocerlo y comprenderlo en su totalidad unitaria. No seremos capaces, desde el exterior, de penetrar en la intimidad de su ser libertad. No es viable una comprensión filosófica ni una explicación científica, total y absoluta, sobre el ser humano. Como anota Jaspers, la compleja estructura existencial hace que el hombre sea siempre más de lo que se sabe sobre él $1^{33}$. O, como apunta Mounier, «mil fotografías combinadas no conforman un hombre que camina, que piensa y que quiere ${ }^{34}$.

El ser humano, cada persona, debe utilizar diversas vías de conocimiento para inquirir sobre sí mismo, para saber algo de sí mismo. No

31 Julián Marías, Mapa del mundo personal, Alianza Editorial, primera reimpresión, 1994, p. 12.

32 Emmanuel Mounier, Op. cit., p. 21.

33 Karl Jaspers, La fe filosófica, Edirorial Losada, Buenos Aires, 1968, p. 54.

34 Emmanuel Mounier, Op. cit., p. 6. 
sólo es posible, como antaño se sostenía, que la vía racional era la única posible para lograr este propósito. La vía no intelectual, como las intuiciones, las emociones o los sentimientos, son también experiencias reveladoras del ser humano. A esta vía de conocimiento Francisco Miró Quesada Cantuarias la define con la expresión ontostesia, en contraposición con la ontognosis que es la vía del conocimiento racional. La ontostesia es la sensibilidad del ser. El autor nos revela, en armonía con el aporte de la filosofía de la existencia, que las vías emocionales adquieren fundamental importancia en la aproximación a nuestro ser personal. Sostiene, por ello, que es unna puerta de entrada preciosa para el estudio del ser del hombre, pues aunque no es una captación cognoscitiva de este ser, es un contacto directo con él, que puede servir para una ulterior penetración intelectual $\aleph^{35}$. Para Heidegger y Sartre la revelación ontostésica de la libertad se da en la angustia ${ }^{36}$. Angustia a la que alude Kierkegaard como "el vértigo de la libertad», es decir, el instante en que "la libertad fija la vista en el abismo de su propia posibilidad y echa mano a la finitud para sostenersen ${ }^{37}$.

A propósito de lo dicho, en los días que corren va adquiriendo carta de ciudadanía el referirse no sólo a una inteligencia lógica o matemática sino, al lado de ellas y de otras formas de inteligencia, el resaltar la inteligencia emocional. Se suele sostener por algunos autores que la «inteligencia emocional» nos permite tomar conciencia de nuestros sentimientos, comprender los sentimientos de los que nos rodean, penetrar en el dinámico meandro de nuestras frustraciones, odios, amores, empatías. La ontostesia nos pone directamente frente a lo que somos.

La libertad, en cuanto núcleo existencial del ser humano, es incognoscible e indemostrable $y$, por consiguiente, indefinible ${ }^{38}$. Sartre confirma esta apreciación cuando afirma que la libertad es indefinible e innombrable" ${ }^{39}$. Si es verdad que la libertad "comprueba mi existencia,

35 Francisco Miró Quesada Cantuarias, Ensayos I (Ontología), Imprenta Santa María, Lima, 1951, pp. 27-28.

36 Martín Heidegger, El ser y el tiempo, p. 217. Para este filósofo la angustia hace patente al ser libre "para la libertad de elegirse y empuñarse a sí mismo".

37 Sören Kierkegaard, El concepto de la angustia, Espasa-Calpe, Buenos Aires, segunda edición, 1943, p. 67.

38 Karl Jaspers, La fe filosófica, p. 56.

39 Jean Paul Sartre, El ser y la nada, III, Editorial Iberoamericana, Buenos Aires, 1949, p.17. 
mi ser, por el contrario, no puede ser objeto de comprobación» ${ }^{40}$. Cada ser humano, utilizando diversas vías de conocimiento, se aproxima a su núcleo existencial. Se sensibiliza y vivencia la libertad mediante un infrecuente movimiento de interiorización. Podemos sentir la libertad, comprobar que somos libres, pero es imposible comunicar la libertad en tanto no es objetiva. La libertad se vive, se capta en la angustia, en momentos culminantes de nuestras vidas, cuando debemos adoptar, por nosotros mismos, decisiones trascendentales que marcan nuestro destino. $\mathrm{O}$, simplemente, no se llega jamás en el curso de la existencia a hacer patente nuestro ser.

Por lo expuesto, como sostiene Jaspers, los seres humanos conocemos mejor lo que "no somos», lo que se ubica en el mundo exterior frente a nosotros, que lo que cada ser humano $\mathrm{es}^{41}$. No obstante que el hombre existe y sabe que existe es, en última instancia, un misterio para sí mismo. El ser humano se convierte por consiguiente «en el máximo misterio cuando vislumbra que en su finitud parecen extenderse hacia el infinito sus posibilidades ${ }^{42}$.

La persona, en cuanto unidad psicosomática sustentada en la libertad, no obstante lo dicho, no puede ser confinada en lo indecible. Como apunta Mounier, una experiencia rica que penetra en el mundo se expresa uen una creación incesante de situaciones, de reglas, y de instituciones». Pero, como sostiene el propio autor, "como este recurso de la persona es indefinido, nada que lo expresa lo agota, nada de cuanto lo condiciona lo sojuzga». La persona es una "actividad de autocreación, de comunicación y de adhesión, que se aprehende y se conoce en un acto, como movimiento de personalización" ${ }^{43}$.

Es importante distinguir, en la unidad de la libertad, los dos instantes en que ella se presenta. La libertad es el ser del hombre. Por ello, sólo la muerte le pone fin. Es una instancia nuclear, subjetiva, insecuestrable. A esta libertad le es inherente su capacidad de convertirse de decisión, en que ella consiste, en acto, en conducta, en comportamiento. Es decir, proyectarse hacia el exterior, ejercitarse. No es lo

40 Gabriel Marcel, El misterio del ser, Editorial Sudamericana, Buenos Aires, 1953, p. 226.

41 Karl Jaspers, $O p$. cit., p. 45.

42 Karl Jaspers, Op. cit., p. 45.

43 Emmanuel Mounier, Op. cit., p.7. 
mismo, por lo tanto, la libertad, en que consiste el ser humano, y la proyección de la libertad que, en el ámbito de las constituciones y los códigos, se le suele designar como "desarrollo de la personalidad». Estos actos, que son manifestaciones exteriores o fenomenalizadas de la libertad, están protegidos por el derecho. Hasta no hace mucho se les conocía también como «las libertades», que merecían ser "garantizadas" por las constituciones políticas.

Este distingo tiene una importante finalidad práctica como es la de comprender que la llamada "capacidad de goce», que es inherente a la libertad, no puede ser objeto de limitación o restricción legal alguna. En cambio, dicha capacidad convertida en acto, en ejercicio, está sujeta a las disposiciones del derecho. Es decir, sólo la capacidad conocida como de ejercicio o de obrar es susceptible de limitación legal ${ }^{44}$. Todos los seres humanos gozan de los mismos derechos.

\subsection{Coexistencialidad y temporalidad del ser humano}

El personalismo descubre al ser humano como un ente coexistencial, que realiza su vida con los «otros» en el seno de la comunidad. Contrariamente a la concepción individualista, para el personalismo es inconcebible el ser humano aislado, incomunicado, encerrado en su propia mismidad. El ser humano está en comunicación, es, de suyo, comunicación. Como sostiene Jaspers, en la comunicación la existencia encuentra su ser al unirse con otra persona. La persona es, por naturaleza, comunicable.

Contrariamente a la posición asumida por el personalismo en concordancia con la estructura existencial del ser humano, el primer cuidado del individualismo, como apunta Mounier, es "centrar al individuo sobre sím. En cambio, el primer cuidado del personalismo, es "descentrarlo para establecerlo en las perspectivas abiertas de la persona». El primer movimiento del ser humano es un movimiento hacia el otro $^{45}$. El primer acto de la persona es suscitar con otros una sociedad

44 No se pudo incluir esta concepción en el artículo $3^{\circ}$ del Código civil vigente. Felizmente, la Comisión que está proyectando en la actualidad una ley de enmiendas ha aprobado una nueva redacción de este numeral a fin de concretar normativamente esta posición.

45 Emmanuel Mounier, Op. cit., p.20. 
de personas, «cuyas estructuras, costumbres, sentimientos y, finalmente, instituciones, estén marcadas por su naturaleza de personas: sociedad cuyas costumbres solamente comenzamos a entrever y esbozar " ${ }^{46}$.

Vivir es convivir. La existencia es coexistencia. Se trata de diversas maneras de expresar que el ser humano no es sólo un ser «individual», singular, único e irrepetible, sino que también, simultáneamente, es un ser «social». La existencia y la coexistencia son las dos dimensiones de la estructura del ser humano. Heidegger lo refiere como un «ser-en-el-mundo", Sartre lo describe como "un-ser-para-el-otro", mientras que Zubiri encuentra que una dimensión ontológica de la persona es la de "ser-con" y Jaspers alude a la "comunicación" como constitutiva de su ser. Todas estas expresiones presentan a la persona como un ser que, necesariamente, tiene que realizarse con los demás en sociedad. Por ello Julián Marías sentencia que «vivir es, a la vez, estar en el mundo y convivir ${ }^{47}$.

Mounier, al mencionar la dimensión coexistencial del ser humano, expresa que "casi se podría decir que sólo existo en la medida que existo para otros, y en última instancia ser es amar». Las otras personas no limitan la realización de la persona sino que, por el contrario, «la hacen ser y desarrollarse». De ahí que afirme que la persona «no existe sino hacia los otros, no se conoce sino por los otros, no se encuentra sino en los otros ${ }^{48}$. Son hermosas y precisas las expresiones de Mounier que transcribimos. Su lectura nos permite comprender mejor la bidimensionalidad del ser humano y, en especial, en qué consiste la dimensión coexistencial del ser humano, su ser social.

La estructura del ser humano no se agota en su bidimensionalidad libertad-coexistencialidad. Es, además, un ser temporal ${ }^{49}$ y, por lo tanto, histórico. Es tiempo existencial ínsito en el tiempo universal. Es libertad coexistencial desplegada en el tiempo existencial. El tiempo existencial aparece con el ser humano en la concepción y se agota en el momento de la muerte. Es el alfa y el omega del hombre. Su existencia terrenal. Es el fugaz instante del vivir humano en el universo son fronteras, en el tiempo infinito.

46 Emmanuel Mounier, Op. cit., p. 21.

47 Julián Marías, Mapa del mundo personal, p.11.

48 Emmanuel Mounier, Op. cit., p. 20.

49 Sobre el tiempo existencial Martín Heidegger, El ser y el tiempo, traducción del alemán por José Gaos, Editorial Fondo de Cultura Económica, México, 1951. 
El ser humano por ser temporal está situado en un lábil presente, tiene pasado y futuro. Es decir, el tiempo que fugó y aquél que está por venir. En el presente, sustentado en su pasado, el ser humano proyecta su vida futura. Si el ser humano no fuese temporal no podría proyectarse, trazar su destino, en cuanto ser libre, contando con los demás en su dimensión coexistencial. Este es el sujeto del derecho, el centro y el eje de la disciplina jurídica. Su creador, destinatario y protagonista.

\subsection{Del Cristianismo a la filosofía de la existencia}

Las verdades expuestas constituyen, como remarca el propio Mounier, el personalismo mismo. Le son inherentes. De ahí que constituya un pleonasmo designar a la civilización que persigue como personalista y comunitaria. Estas verdades, añade el autor, expresan, frente al individualismo y al idealismo persistentes, que «el sujeto no se nutre por autodigestión, que nadie posee sino lo que da, o aquello a lo que se da, que nadie alcanza su salvación totalmente solo, ni social ni espiritualmente" ${ }^{50}$.

El Cristianismo, como nos lo recuerda Mounier, aporta de golpe, entre los anteriores tanteos de aproximación al ser humano, «una visión decisiva de la persona». Como expresa con acierto, hoy día no se aprecia en toda su magnitud el escándalo que esa noción aportada por el Cristianismo significó para el pensamiento y la sensibilidad de los griegos. El Cristianismo nos presenta un ser humano libre, capaz de perderse o salvarse. El pecado no sería comprendido si el hombre no fuera libre.

Recordamos el impacto que nos causó cuando ingresamos a la Universidad en 1943 la lectura de algún libro -cuyo título se perdió en la bruma del tiempo- que reportaba en sus páginas un revelador debate entre Bossuet y San Agustín sobre la libertad del hombre y la intervención de Dios en su vida. Sostenía el primero, comparando al ser humano con un reloj, que Dios lo pone en marcha y lo abandona a su suerte. San Agustín, por el contrario, sostenía que Dios intervenía en la vida del hombre siempre que éste reclamara su ayuda a través de la oración. Es decir, que si se le pedía con convicción, podía adelantar o retrasar el reloj si se presentase algún contratiempo en su mecánico discurrir. En 
ello radica, precisamente, el valor de la oración, del evangélico «pedid y recibiréis».

Los aportes del Cristianismo quedaron confinados en el campo de la teología, por lo que no trascendieron mayormente a la filosofía. De ahí que se refiera al ser humano como "un ser racional", sin alusión alguna a su núcleo existencial que es la libertad espiritual. De ahí que Boecio, en el siglo VI d.c. lo concibe como «una unidad de substancia racional». Así nos lo enseñaron en su momento. Probablemente así se seguirá enseñando en la actualidad.

Más allá de las contribuciones de algunos filósofos en lo que concierne al conocimiento de la persona, en el decurso de la historia posterior a la aparición del Cristianismo, corresponde a la filosofía existencial, como está dicho, el habernos brindado hallazgos de extrema importancia para una mejor aprehensión de lo que es la persona. Así lo reconoce el propio Mounier cuando manifiesta «que el existencialismo ha contribuido en gran medida a reavivar problemas personalistas: la libertad, la interioridad, la comunicación, el sentido de la historia». Entre los filósofos existencialistas se refiere, en particular a Marcel, de raigambre cristiana, y a Jaspers, agnóstico, como aquellos que aportan una contribución capital a la descripción de las estructuras del universo personal ${ }^{51}$.

Desde que tomamos contacto con la filosofía de la existencia en la década de los años cuarenta, siendo alumnos de la que fuera Facultad de Letras de la Universidad Nacional Mayor de San Marcos de Lima, comprendimos la trascendencia de sus aportes de la filosofía de la existencia en lo atinente a un más próximo y profundo conocimiento de las estructuras del ser humano y, ciertamente, en cuanto a un esclarecimiento de lo que significa el derecho «en» $y$ "para» la vida humana. Personalmente, los hallazgos del existencialismo, como lo hemos puesto de manifiesto, nos fueron de capital utilidad para bosquejar y sustentar en 1950 la teoría tridimensional del derecho así como para comprender el derecho bajo una óptica personalista. Todo ello se comprobó, además, en el laboratorio de nuestra propia experiencia personal, a través de nuestras vivencias y de la atenta observación de la realidad.

51 Emmanuel Mounier, Op. cit., p. 11. 
Más allá de las modas filosóficas, de los nuevos aportes enriquecedores del conocimiento del ser humano, no podemos prescindir de la decisiva contribución de la filosofía de la existencia en este inacabado esfuerzo por aproximarnos al ser humano. En este sentido, cabe señalar, coincidiendo con lo expresado en 1985 por un autor español, que la "onda sísmica» del existencialismo "sacude el alma de varias generaciones de intelectuales» y que «aún hoy, cuando el reflujo de su impacto se hace patente, permanece oculta su huella en la atmósfera general que impregna la conciencia del hombre actual ${ }^{52}$. Corroboramos esta apreciación desde la perspectiva en que históricamente estamos ubicados, o sea, aquella de comienzos del siglo XXI.

\section{Personalismo y derecho}

El personalismo, que surge de la crisis mundial de 1929, pretende humanizar el derecho, insertar la solidaridad en la vida de relación, preservar la libertad, sustentar la dignidad de la persona, proteger la iniciativa individual. El personalismo aparece como una comprensible y necesaria reacción contra el liberalismo y el socialismo extremos y dogmáticos. El personalismo intenta superar los materialismos que se expresan en el liberalismo y en el socialismo «despojándolos de sus excesos extremistas en el sentido del individuo o la colectividad, ${ }^{53}$. El personalismo pretende conciliar y armonizar los fines individuales y sociales «sobre la base del reconocimiento, el respeto y el rango preferencial que en la jerarquía de los valores corresponde a la persona humana ${ }^{54}$. Ello, reconociendo la estructura bidimensional del ser humano en cuanto, simultáneamente, es un ser individual sustentado en su libertad y un ser social, coexistencial, inserto estructuralmente en la sociedad.

El personalismo, apoyado en la filosofía de la existencia, nos proporciona la oportunidad de comprender, a plenitud, el sentido del

52 Pedro Fontán Jubero, Los existencialismos: clave para su comprensión, Editorial Cincel, Madrid, 1985, p. 17.

53 Lino Rodríguez Arias-Bustamante, Del derecho liberal al derecho comunitario, p.4.

54 Lino Rodríguez Arias-Bustamante, Del derecho liberal al derecho comunitario, citando a José Castán Tobeñas, p. 4. 
derecho como protector de la libertad en que ontológicamente consentimos dentro del bien común, que es el bien de todos y el de cada uno.

$\mathrm{Al}$ exaltar la libertad aprehendemos que el derecho es creado por el hombre y para el hombre a fin de crear las condiciones exteriores necesarias para realizar su proyecto de vida. El derecho sólo puede ser creado y propuesto a seres libres. Los seres humanos en sociedad tienen la opción de decidir, en cuanto libres, de cumplir con su propio deber o incumplirlo. Sólo se pueden proponer permisiones y prohibiciones a seres libres. Por lo expuesto, sin comprender al ser humano como un ser libertad no entenderíamos que sea el derecho. El derecho protege la libertad del ser humano a fin de permitirle vivir de acuerdo a su personal proyecto de vida.

El derecho es una exigencia existencial del ser humano. Ello es comprensible si tenemos en cuenta su estructura coexistencial. El ser humano no puede convivir, en cuanto ser social, sin reglas de conducta. Las conductas humanas intersubjetivas deben ser valoradas para ser jurídicamente normadas. Por ello, decimos, el derecho es una exigencia existencial. El ser humano no podría vivir y convivir sin el derecho.

La nueva concepción del derecho, el viaje a sus entrañas, permitieron la elaboración de la teoría tridimensional. El derecho no puede explicarse ni comprenderse como una totalidad a través de visiones que, sin dejar de ser ciertas, son fragmentarias, parciales. Por ello ni el formalismo, ni el jusnaturalismo ni el sociologismo, por sí solos, logran brindar una versión satisfactoria de cuál sea el objeto de estudio de la disciplina jurídica. Estas concepciones parciales del derecho son superadas desde una óptica tridimensional. Es así que para el tridimensionalismo la noción unitaria del derecho surge de la interacción dinámica de vida humana, valores y normas jurídicas. El derecho no es sólo vida humana coexistencial, ni sólo valores ni sólo normas jurídicas. Ninguno de estos tres objetos, por sí sólo, es derecho, pero ninguno de ellos puede faltar cuando pretendemos comprender que sea el derecho. La concepción tridimensional es fiel a la realidad, no se aparta de ella para obtener sus conclusiones ${ }^{55}$.

55 Ver Carlos Fernández Sessarego, El derecho como libertad, segunda edición, Universidad de Lima, Lima, 1987 y Derecho y persona, tercera edición, Editorial Grigley, Lima, 1998. 
El personalismo, como se ha señalado, permite centrar el derecho en la persona. Ella es el objeto primario de su protección en cuanto es fin en sí misma. El patrimonio, indispensable para el vivir, es sólo un instrumento a su servicio, del cual se vale, entre otros elementos, para realizarse.

\section{Del individualismo del Código civil de 1936 al personalismo del Código de 1984}

\subsection{El personalismo del Código Civil de 1984}

El Código civil de 1984 se inspiró, en grandes tramos, en el personalismo humanista. Así lo reconocen los juristas nacionales y extranjeros que lo han analizado y estudiado en profundidad. Las opiniones que de ellos glosaremos en las páginas siguientes así lo demuestran. Sus juicios críticos constituyen un invalorable testimonio en cuanto a determinar la inspiración personalista del Código civil de 1984 y de sus aportes innovadores.

Cómo dicho Código fue una obra colectiva, no siempre las instituciones o las normas que lo integran responden plenamente a una concepción personalista. Ella deja una huella más visible, más elocuente, en ciertos libros o en determinadas instituciones, mientras se difumina o desaparece en otras. Existen, por ellos «baches», rezagos de un individualismo-patrimonialista. El Código civil, por la razón expuesta, no es parejo al asumir el personalismo. No siempre se atiende al ser humano como un ente privilegiado.

Ello también es explicable porque no fue tarea fácil cambiar plenamente la mentalidad de los codificadores que fuimos entrenados, desde nuestra formación universitaria, a reflexionar bajo los parámetros de una concepción individualista-patrimonialista alojada en la tradición y que se plasmaba en las normas de la codificación comparada, incluyendo el Código civil peruano de 1936. Transitar de una concepción individualista y patrimonialista a una humanista supone un vuelvo ideológico de tal trascendencia que no siempre se logra asimilar ni rápida ni plenamente. Y, por cierto, existen juristas que no aceptan el cambio, que no sensibilizan el valor y la consiguiente primacía de la persona humana. 
Es útil ilustrar lo dicho con algún ejemplo revelador. El artículo $584^{\circ}$ dispone que para ser declarado pródigo se deben cumplir dos requisitos. El primero, que tenga cónyuge o herederos forzosos y, el segundo, que haya dilapidado bienes que exceden de su porción disponible. Debemos partir del hecho que la prodigalidad es un trastorno mental. Ello implica que a quien debe atenderse preferentemente es a la persona del dilapidador. Para ello no es necesario que tenga cónyuge o herederos forzosos ni, por supuesto, hay que esperar que dilapide hasta un tercio de su patrimonio. La atención a la persona debe ser inmediata y no estar en función de otros requisitos de carácter patrimonial. Ella debe iniciarse, sin dilación, apenas se tenga conciencia del trastorno mental que sufre el pródigo para proceder de inmediato el tratamiento médico que corresponda. No hay que aguardar el cumplimiento de "plazos" marcados por una matemática pérdida patrimonial.

Análoga situación a la reseñada en el párrafo anterior se hace patente en el caso del artículo $585^{\circ}$ del mencionado cuerpo legal. Según este dispositivo, para ser declarado incapaz por mala gestión, teniendo cónyuges o herederos forzosos, se debe esperar a que la persona que sufre este específico trastorno mental pierda por dicha causa la mitad de sus bienes. En este caso, el tratamiento médico del ser humano mal gestor no puede estar condicionado a que tenga dichos parientes ni a perder la mitad de su patrimonio. Se observa que, en ambas situaciones, la preocupación del codificador es proteger preferentemente los intereses patrimoniales de los parientes $y$, en un segundo instante, a la persona humana afectada por un trastorno mental. El caso no exige un mayor comentario.

Cabe señalar, no obstante lo dicho, que los casos expuestos y algunos otros más que hemos detectado no invalidan la inspiración personalista del Código civil vigente. Su orientación humanista es indiscutible y ella ha sido valorada por eminentes juristas allende nuestras fronteras. La huella histórica del Código civil de 1984 será, por ello, indeleble. Estamos seguros que dicho cuerpo legal soportará, incólume, los embates y los esfuerzos que puedan hacerse para debilitar la inspiración que lo define y caracteriza.

\subsection{La apreciación de los juristas nacionales}

Es necesario recordar la opinión del maestro José León Barandiarán sobre el Código civil peruano de 1984. Al referirse al Libro Primero 
sobre el Derecho de las Personas expresa "que está considerada como una parte excelente" y que "dentro y en comparación a los otros Códigos vigentes se sabe que el Libro del Derecho de las Personas en nuestro Código es el mejor entre los códigos del mundo». León Barandiarán, con la sabiduría de que hacía gala, agrega al respecto que «ningún otro código del mundo que hemos revisado para nuestra ponencia en esta parte es tan completo como la ponencia de los derechos de la personalidad [...]».

El maestro León Barandiarán nos ofrece un valioso testimonio cuando relata que «cuando se produjo en 1985 el Congreso Internacional organizado por la Universidad de Lima, los profesores extranjeros, sobre todo los italianos, estimaron que el peruano era el mejor Código del mundo, especialmente por esta parte del Derecho de las Personas ${ }^{56}$.

Otros destacados juristas peruanos han manifestado también sus comentarios respecto a la inspiración humanista de nuestro Código civil de 1984. Entre ellos podemos citar a Max Arias Schreiber, Fernando Vidal, Juan Espinoza Espinoza, Yuri Vega Mere, entre otros.

Max Arias Schreiber ha destacado como cuando se inició el trabajo de redacción del Código civil, en un lejano 1965, la mayoría de los miembros de la Comisión Reformadora, no obstante sus calidades académicas y profesionales, no habían aún tenido noticias de la concepción personalista del derecho. Ello, expresa, en virtud de que todos los componentes de dicha Comisión, incluyendo al que esto escribe, fueron formados dentro de los parámetros individualistas-patrimonialistas del derogado Código civil de 1936. En este sentido nos ofrece un revelador testimonio sobre como fue gestándose, a través del tiempo que duró la elaboración del Código civil de 1984, una concepción humanista de sus instituciones. Nos dice a este propósito que «aún cuando en sus orígenes el nuevo Código se inspiraba en la concepción liberal e individualista de la mayoría de los miembros de la Comisión

56 Estas apreciaciones fueron expresadas en la presentación del libro del autor Derecho de las Personas, Exposición de Motivos y Comentarios al Libro Primero del Código civil peruano en el año de 1986 y que aparece en el volumen titulado "Estudios Jurídicos en honor de los Profesores Carlos Fernández Sessarego y Max Arias Schreiber Pezet", Editorial Cuzco, Lima, 1988, p, 413. Esta presentación se reproduce en la séptima edición del mencionado libro del autor publicado por la Editorial Grigley en 1998. 
Reformadora -lo que desde luego era explicable debido a su formación- lentamente fue filtrándose una concepción de corte netamente humanista y social [...]». Fue así que "en suma mientras en el Código de 1936 predominaba un criterio que se ha calificado de patrimonialista, el Código actual tiene al ser humano como centro de imputación del derecho y lo material -siendo desde luego muy importante- es un medio o instrumento de aquel. Se dice entonces que este Código es humanista por excelencia ${ }^{57}$.

Fernando Vidal Ramírez, por su parte, ha puesto de relieve el sentido renovador del Código civil en este singular aspecto al reconocer que «en el ordenamiento del Derecho de las Personas, el Código pone énfasis en una concepción humanista [...],$^{58}$.

Yuri Vega Mere, deja constancia que el Código civil del 84 «ha sido (y es) objeto de admiración en distintos y múltiples países latinoamericanos y europeos. En particular, en la República Argentina, cuyos más destacados exponentes de la civilística nos han visitado a lo largo de estos años, ha servido de fuente para los proyectos de unificación del derecho privado, lo que dice bastante de las bondades de nuestro Código" " ${ }^{59}$. El autor expresa que en su concepto «el Código abre una nueva época, que la historia del derecho evaluará con mayor objetividad». El Código, señala, «ha sido considerado original en diversos aspectos y ha sido citado y explicado en el extranjero". A manera de testimonio personal, manifiesta que "este hecho lo hemos vivido, con gran satisfacción, en Italia» ${ }^{60}$. Destaca, al respecto, que nuestro Código "contiene cuantiosos aportes que han sido objeto de comentarios y loas por parte de juristas de diversos países» y que no cree equivocarse «en señalar que ellos se aprecian, básicamente, en materia de personas y contratos ${ }^{61}$.

57 Max Arias Schreiber, Luces y sombras del Código civil, Tomo I, Librería Studium, Lima, 1991, p. 19.

58 Fernando Vidal Ramírez, «El artículo $1^{\circ}$ del Código civil peruano y su criterio sobre el comienzo de la vida humana», Themis, Revista de Derecho, $\mathrm{N}^{\circ} 30$, Universidad Católica, Lima, noviembre de 1994, p. 55.

59 Yuri Vega Mere, Derecho Privado, Editorial Grigley, Lima, Tomo I, 1996, pp. 103-104.

60 Yuri Vega Mere, op. cit., p. 105.

61 Yuri Vega Mere, op. cit, p. 109. 


\subsection{Comentarios de civilistas allende nuestras fronteras}

Numerosos juristas, tanto nacionales como extranjeros, a través de libros, revistas y conferencias han destacado el original aporte personalista del Código civil de 1984 y la ruptura ideológica que él representa en relación con el pasado inmediato. Según algunos, este significativo vuelco abre una nueva era en la codificación comparada. Se supera, así, una antigua tradición que encuentra su origen en el Código civil de los franceses de 1804, inspirador ideológico de la codificación de los siglos XIX y del siglo XX. En alguna oportunidad hemos dejado expresa constancia que, más allá de los aportes o bondades que pueda ofrecer el Código civil de 1984, lo más rescatable en él es el haber podido plasmar normativamente, en grandes tramos, una concepción personalista del derecho ${ }^{62}$. Nuestra opinión es compartida por algunos finos, agudos y cultos intérpretes de nuestro Código civil.

Entre los juristas del país probablemente ninguno desconoce el contraste que existe entre el tratamiento de la protección de la persona dispensado por el Código civil de 1936 y aquel brindado por el Código de 1984. Ello es elocuente por lo no requiere mayor demostración. Basta leer y comparar los textos del Libro Primero de ambos cuerpos legales para advertirlo.

Por ello, lo importante es conocer la opinión que sobre el Código civil de 1984 ha sido formulada por civilistas y comparatistas extranjeros de renombre. Muchos de ellos, apenas promulgado el Código civil de 1984, lo analizaron y vertieron sus comentarios en congresos internacionales o en diversas publicaciones. Ello, sin duda, es motivo de satisfacción, lo que no significa, por cierto, que no continuemos atentos a los reclamos de la realidad con el objetivo muy preciso de contribuir a adecuar el contenido de las normas jurídicas a dichas urgencias.

Hemos escogido, al acaso, algunos de dichos comentarios, los mismos que transcribimos en las páginas siguientes. A manera de introducción señalaremos, por ejemplo, que el notable jurista argentino Atilio A. Alterini, refiriéndose al Código del 84, al destacar que en los tiempos que corren «se va llegando con muchos tropiezos" a una concep-

62 Carlos Fernández Sessarego, "¿Qué tiene de original el Código civil peruano de 1984?», en la revista Testimonio, Lima, diciembre de 1994. 
ción personalista del derecho, expresa que en este Código, y en coincidencia con la Constitución peruana de 1979, se considera a la persona humana como el bien supremo del derecho, de la sociedad y del Estado $^{63}$.

Por su parte, el jurista italiano Sandro Schipani, en una intervención que tuviera en el Congreso Internacional reunido en Lima en 1988 y organizado por el Colegio de Abogados de esa ciudad, reiterando opiniones vertidas en otra oportunidad, sostuvo que "del Código civil de 1984 ha sido también subrayada su contribución a la plasmación en precisas disposiciones normativas, del principio de la centralidad de la persona para el derecho [...]" ${ }^{64}$. La síntesis que ensaya Schipani refleja perfectamente el principio personalista que inspira el Código del 84.

El creativo jurista italiano Francesco D. Busnelli, profesor de la Universidad de Pisa, al referirse a tutela dispensada a la persona humana por el artículo $17^{\circ}$ del Código de 1984 expresa que, a pesar que su formulación definitiva ha perdido parte de la fuerza innovativa con la que fue proyectado por el ponente del Libro Primero, «permanece todavía como una norma importante». $Y$, añade, que es «según me consta, la primera vea que un código otorga un alcance general a la acción inhibitoria en el cuadro de la tutela de los derechos de la personalidad, modificando la tradición codificadora -a la cual se uniforma también el vigente Código civil italiano- que concibe dicha acción como remedio ocasional y no siempre referido a la tutela de la persona ${ }^{65}$.

\subsection{Las reflexiones de Fernando Fueyo Laneri}

Para destacar la diferencia existente entre el tratamiento del derecho de las personas en los Código civiles peruanos de 1936 y de 1984, hemos considerado pertinente glosar los comentarios que esta ostensible si-

63 Atilio Alterini A., “Daño a la persona», en Temas de Derecho Privado, Colegio de Escribanos de Buenos Aires, 1993, p. 34.

64 Sandro Schipani, discurso publicado en Nuevas tendencias y perspectivas del Derecho Privado y el sistema jurídico latinoamericano, Editorial Cuzco, Lima, 1990, p. 15 ,

65 Francesco Busnelli D. «La tutela civil de la persona humana: una comparación entre el Código argentino de Vélez y el nuevo Código civil peruano" en Tendencias y perspectivas del Derecho Privado y el sistema jurídico latinoamericano. p. 51 
tuación le merecen a un jurista de la talla del que fuera Fernando Fueyo Laneri, el civilista más destacado del siglo XX en el mundo jurídico chileno.

Fueyo Laneri, el eminente y recordado civilista chileno, al constatar la evolución que venía produciéndose en el derecho a través de un insensible tránsito de un exacerbado individualismo patrimonialista a un personalismo solidario, señala que «sin distinguir épocas o ambientes en particular, lo cierto es que, habida cuenta de que el Derecho civil se polariza firmemente en torno a la persona, y que ésta va logrando en aquél, día a día, el tratamiento hondo e integral que verdaderamente le corresponde, como se comprueba en lo legislativo con el reciente ejemplo que nos ofrece el Código civil peruano de $1984{ }^{66}{ }^{6}$. Nuestro Código civil vigente resulta así, según Fueyo Laneri, un claro ejemplo, una muestra concreta, de un instante feliz en el incesante proceso de evolución que, paulatinamente, venía produciéndose en el derecho en el curso del siglo XX donde, a partir de una concepción que lo hacia girar en torno al patrimonio, se proyecta hacia otra de carácter humanista en la cual la persona se constituye en su centro y eje.

Para el civilista chileno antes mencionado, el Código civil peruano de 1984 tiene el mérito indiscutible de, adelantándose a otros cuerpos legales, concretar normativamente la nueva concepción personalista que se abría lentamente paso a través de la doctrina. Consideramos, desde nuestro punto de vista, que el aporte personalista destacado por Fueyo Laneri es el mayor logro de nuestro Código civil de 1984, el mismo que hay que defender y mantener ante los embates de un exagerado y extremista individualismo neoliberal así como de toda laya de materialismos pragmáticos, cualquiera fuera su signo ideológico.

Fueyo Laneri pone de manifiesto, a través de un acucioso estudio comparativo, el evidente contraste existente entre el tratamiento legislativo de los derechos de la persona que otorgaba el Código civil derogado de 1936 y aquel que le dispensa el Código civil de 1984. En este sentido, se muestra contundente en cuanto a sus apreciaciones sobre el significado y alcances del Código Civil de 1936 en lo que concierne al tratamiento de tales derechos. Es así que afirma, en esclarecedora sín-

66 Fernando Fueyo Laneri, Sobre el derecho de la persona a propósito del nuevo Código de la República del Perú, en El Código civil peruano y el sistema jurídico Latinoamericano. Cultural Cuzco, Lima, 1986, p. 172. 
tesis, que «las disposiciones legales que intentaban infructuosamente regular el derecho de las personas en el Código Civil derogado de 1936, y que había regido en el Perú desde el 30 de agosto de 1936, aparecen no sólo como incompletas, insuficientes y obsoletas, sino francamente más bien como magras e ingenuas".

Luego de los calificativos transcritos en lo que atañe al Código civil de 1936, Fueyo Laneri agregaba, refiriéndose al actual Código civil de 1984, que uel progreso logrado a este respecto resulta, pues, extraordinario y hemos de felicitarnos por ello" ${ }^{67}$. El autor, con los elocuentes adjetivos que utiliza para describir la orfandad en el tratamiento del derecho de las personas en el derogado Código Civil de 1936 deja constancia, mediante su autorizada opinión, de la notoria diferencia existente entre los Códigos civiles de 1936 y de 1984 en lo que atañe al interés y énfasis que ambos cuerpos legales ponen en lo que concierne a la protección de la persona humana.

La valiosa y objetiva apreciación de Fueyo Laneri, quien fuera el más completo y versado civilista chileno de los últimos cincuenta años, es inobjetable. Ella nos muestra, desde la perspectiva que otorga la distancia, el notable contraste entre las disposiciones del Código civil de 1936 en materia del derecho de las personas, que resultaban, utilizando sus propias expresiones, incompletas, insuficientes, obsoletas, magras e ingenuas". La riqueza descriptiva que utiliza Fueyo Laneri nos releva de mayor comentario a la vez que justifica el análisis crítico que nos mereció, en un lejano 1964, el contenido del Libro Primero del Código de 1936. Al respecto, en aquel año redactamos un ensayo proponiendo decididamente su reestructuración ${ }^{68}$.

67 Fernando Fueyo Laneri, Sobre el derecho de las personas a propósito del nuevo Código de la República del Perú en El Código civil peruano y el sistema jurídico latinoamericano, p. 174.

68 Carlos Fernández Sessarego, “Consideraciones sistemáticas preliminares para la revisión del Libro Primero del Código civil peruano». Este ensayo tuvo en su momento una amplia difusión. Fue publicado en la revista Mercurio Peruano, Lima, mayo-junio, 1964; en el Boletín del Instituto de Derecho Comparado del Perú, Lima, enero-diciembre 1965 y en el volumen Nuevas orientaciones en el derecho, Colegio de Abogados de Lima, Lima, 1965. Posteriormente fue recogido como el primer capítulo del libro del autor titulado La persona en la doctrina jurídica contemporánea, editado por la Universidad de Lima, Lima, 1984. Este ensayo fue considerado por los profesores Fernando Vidal Ramírez y Carlos Torres y Torres Lara como el único publicado, con sentido estrictamente crítico, sobre el Código civil de 1936. 
Los certeros comentarios de Fueyo Laneri, que datan de 1985, como está dicho, nos relevan de mayores precisiones. No obstante, habría que agregar que el contraste que se advierte en cuanto al notable número de figuras jurídicas incorporadas en el nuevo Libro Primero del Código civil de 1984 y las magras disposiciones del Código de 1936, ponen también de manifiesto, como se ha apuntado, un viraje radical entre los supuestos casi exclusivamente individualistas que inspiraron el Código civil derogado y los de carácter personalista que subyacen en la mayoría de las normas del Código civil vigente.

Fueyo Laneri, al referirse al Código civil peruano de 1984 en su conjunto, expresa que un Código "como éste, que es de extraordinario número de libros, nada menos que diez, acusa, simultáneamente, un notable realce de las personas naturales, en una Sección Primera, y las jurídicas, en una Sección Segunda». Al verificar este hecho remarca lo que ha sido también enfatizado por numerosos comentaristas de nuestro Código civil - que: «El derecho de las personas, que así se denomina el Libro I, encabeza y domina realmente el conjunto de Libros de que se compone el Código [...] $\aleph^{69}$. Con estas expresiones el jurista chileno pone de manifiesto la preeminencia que en el Código civil peruano de 1984 ha adquirido el otrora disminuido derecho de las personas.

Como síntesis de sus comentarios el civilista chileno, al referirse al cambio ideológico y técnico que representa el Código civil de 1984 con referencia al derogado Código civil de 1936 y a nivel de la codificación comparada, señala que «el cambio experimentado ha de ser considerado notable y servirá de magnífico precedente para futuras reformas legislativas en otras naciones $[\ldots]]^{70}$. En este sentido se ha cumplido el vaticinio de Fueyo Laneri desde que otros Código civiles han tomado como uno de sus modelos el Código civil peruano de 1984. Es el caso, entre otros, de Argentina y Puerto Rico.

Los aportes y, sobre todo, la inspiración personalista del Código del 84, movieron a Fueyo a presentar ante el Congreso Internacional celebrado en Lima entre el 9 y el 11 de agosto de 1985 bajo el nombre de

69 Fernando Fueyo Laneri, «Sobre el derecho de las personas en el nuevo Código de la República del Perú» en El Código civil peruano y el sistema jurídico latinoamericano, p. 174.

70 Fernando Fueyo Laneri, Op. cit., p. 173. 
«El Código civil peruano y el sistema jurídico latinoamericano» una moción tendente a la elaboración de un Libro sobre Derechos de la Persona «que pudiera proponerse a los Estados de América Latina como nueva legislación para su eventual incorporación al Código civil respectivo». Sugería en la moción «iniciar los estudios teniéndose a la vista el texto del Libro Primero del Código civil peruano, cuya bondad técnica se ha ponderado en este Congreso por sus participantes" y que los profesores de Derecho Civil se reunieran, lo antes posible, para tal efecto.

La moción presentada por Fueyo Laneri fue aprobada por unanimidad en la sesión de clausura del mencionado Congreso Internacional. En la ciudad de Bogotá en 1987, organizada por la Universidad Externado de Colombia, se produjo la primera reunión. Las ponencias presentadas se publicaron, años después, en el volumen titulado «La persona en el sistema jurídico latinoamericano» ${ }^{71}$. Lamentablemente, la iniciativa quedó trunca pues desde aquella fecha no nos hemos vuelto a reunir.

Finalmente, el jurista chileno manifiesta que el Código civil peruano «supera a los códigos civiles de Latinoamérica en lo que concierne a esta materia (derecho de las personas) códigos que, siendo todos bastante antiguos para nuestro tiempo, no han recogido las correspondientes concepciones contemporáneas que circulan en los libros nacionales o extranjeros, de un modo u otro, a veces imperfectamente y con deficiente sistematización [...]» ${ }^{72}$.

\subsection{La opinión de Pietro Rescigno}

Para el maestro y tratadista italiano Pietro Rescigno, el Código civil peruano de 1984 «es un texto legislativo de gran interés para el jurista de Europa continental y, en particular, para el italianos ${ }^{73}$. Al comparar el Libro Primero del mencionado Código con la Constitución de 1979 -que, según su parecer, sufre de excesiva prolijidad-, señala que asume

71 La persona en el sistema jurídico latinoamericano, Universidad Externado de Colombia, 1995.

72 Fernando Fueyo Laneri, Op. cit., p. 192.

73 Pietro Rescigno, "Comentarios al Libro del Derecho de las Personas del nuevo Código civil peruano de 1984", en El Código civil peruano y el sistema jurídico latinoamericano, p. 235. 
"una posición de notable interés» ${ }^{74}$. Un interés que se centra no sólo en las novedades introducidas sino en su enfoque personalista.

El profesor de la Universidad de Roma, al recordar que el Código civil italiano de 1942 es una obra "de rigurosa formulación teórica, ciertamente entre las más notables del siglo», sostiene que la lectura actualizada del Código del 42, cumplida a la luz de la aplicación que la jurisprudencia y la doctrina han realizado en cuarenta años, ha ejercido, como ya se ha puesto en evidencia, decisiva influencia sobre el Código civil peruano, sin querer negar con ello el concurso de otros motivos inspiradores». Sin embargo, al constatar este hecho pone de manifiesto «la utilidad que significa una lectura atenta del código peruano destinada a buscar y obtener respuestas a preguntas y problemas que entre nosotros (los juristas italianos) adquieren carácter de actualidad ${ }^{75}$. Es de suma importancia recoger, en todo su valor, esta autorizada apreciación de Rescigno sobre el Código civil peruano. De ella se desprende la utilidad que este cuerpo legal tiene para el estudioso italiano -muchos de los cuales de alguna manera se han ocupado de este Código- que se interesa, como señala Rescigno, en hallar soluciones a problemas de actualidad aún no resueltos en la península.

En el sentido antes indicado, al referirse al Código de 1984 el maestro italiano reconoce que "con particular riqueza, a veces inclusive con excesiva abundancia tratándose del Libro del Derecho de las Personas, de él puede también extraer soluciones el lector europeo ligado a códigos más antiguos que aquel italiano ${ }^{76}$. Las expresiones de Rescigno constituyen un desinteresado elogio que obliga a mantener la inspiración humanista del Código y, simultáneamente, a revisar periódicamente sus instituciones para adecuarlas a las exigencias de la realidad.

Cabe destacar la opinión de Rescigno, transcrita en precedencia, en el sentido que al jurista italiano y al europeo, en general, le resulta de utilidad el estudio de un Código civil como el peruano de 1984 en tanto puede encontrar en su texto soluciones a cuestiones que aún están pendientes de resolución en el ámbito jurídico de un país como Italia. Rescigno, en los múltiples coloquios sostenidos con él en más de una década, puso siempre en evidencia no sólo los aportes del Código de

74 Pietro Rescigno, Op. cit., p. 238.

75 Pietro Rescigno, Op. cit., p. 235.

76 Pietro Rescigno, Op. cit., p. 236. 
1984 sino, especialmente, enfatizó la inédita propuesta personalista que ofrece este cuerpo legal. No podía ocultar su asombro que ello proviniera de un Código civil elaborado en un lejano país en vías de desarrollo.

Siete años después de haber vertido las apreciaciones anteriormente glosadas, Rescigno vuelve a ocuparse del Código civil peruano de 1984 con la hondura de pensamiento que lo caracterizan. Esta vez fue en un extraordinario Congreso Internacional reunido en la Universidad de Génova en conmemoración de los quinientos años del encuentro de dos mundos. En esta singular ocasión, Rescigno expresó, a título de testimonio personal, que «el conocimiento del área latinoamericana ha pasado por mí, sobre todo, a través de la lectura del Código peruano", al que consideró «entre los más modernos y mejor elaborados del lejano Continente» ${ }^{77}$. Por ello, estimó que el Código civil peruano "constituye un observatorio ideal, porque se advierte, con riqueza y sensibilidad, una atención a la materia de las personas, físicas y jurídicas ${ }^{78}$. Como se advierte, el maestro europeo reafirma, en esta nueva oportunidad, similares positivos comentarios a los que vertiera en Lima en el año de 1985 sobre el Código civil peruano de 1984 y su Libro Primero sobre el Derecho de las Personas.

Rescigno apunta que «colocar como apertura del Código el Derecho de las Personas significa resaltar la prioridad y centralidad de la persona ${ }^{79}$. El profesor de la Universidad de Roma se explica este hecho en el sentido que «se trata de una opción que corresponde a precisas concepciones ideológicas recordadas y resumidas en la alusión que se ha efectuado en el Congreso a la consideración de los hechos, valores y de las normas en la obra legislativa así como en el trabajo del intérprete» ${ }^{80}$. Las precisas concepciones ideológicas a que se refiere Rescigno son el personalismo y el tridimensionalismo jurídico. Con su fina y honda percepción el profesor italiano ha logrado aprehender las raíces ideológicas del Código de 1984.

77 Pietro Rescigno, "La circolazione dei modelli giuridici europei nel mondo latinoamericano", en Il diritto dei nuovi mondi, Cedam, Génova, 1994, p. 166.

78 Pietro Rescigno, Op. cit., p. 172.

79 Pietro Rescigno, Op. cit., p. 240.

80 Pietro Rescigno, Op. cit., p. 240. 


\subsection{La posición de Víctor Pérez Vargas}

El destacado jurista costarricense Víctor Pérez Vargas, en la ponencia que presentara al Congreso Internacional sobre «Los diez años del Código civil: balance y perspectivas», organizado por la Universidad de Lima en setiembre de 1994 expresó, refiriéndose a este Código que "tras décadas de estancamiento legislativo el Derecho Privado en América Latina, el nuevo Código ha reivindicado el Derecho Civil como estructura legislativa a favor de la persona y de sus cualidades esenciales». Al recordar que "muchos juristas extranjeros han elogiado la contribución del Código civil del Perú y que los propios juristas peruanos consideran que el mejor aporte del Código civil peruano es el Libro de las Personas», concluye manifestando que "en mi criterio, el gran valor del Código civil peruano es su contribución a la integración de nuestros pueblos sobre una base axiológica personalista ${ }^{81}$. Como lo hemos puesto en evidencia, coincidimos plenamente con la apreciación del profesor de la Universidad de Costa Rica cuando expresa que la mayor contribución del Código civil peruano de 1984 es el nuevo modelo que ofrece sustentado en una concepción personalista.

Pérez Vargas realiza un interesante análisis de los principios personalistas contenidos en el Código civil del 84 y de sus aportes a la codificación comparada. Como síntesis conclusiva de sus apreciaciones manifiesta que dicho Código significa «un salto axiológico cualitativo que ha dado con este monumento jurídico el mismo sistema latinoamericano, ya que el Código peruano ha iluminado con su doctrina personalista todo el Derecho civil latinoamericano». Desde nuestra perspectiva, más allá de los aportes novedosos que los críticos y comentaristas hayan encontrado en el Código civil peruano del 84 en cuanto al Derecho de las Personas, aquello de mayor importancia, lo trascendente en el tiempo es, precisamente, el vuelco que significa abandonar, hasta donde ello ha sido posible y aconsejable, la exclusiva inspiración individualista proveniente del Código civil de los franceses de 1804 para sustituirla, con convicción, por una concepción personalista y solidaria.

81 Víctor Pérez Vargas, "El aporte personalista del Código civil peruano», en Los diez años del Código civil: balance y perspectivas, Universidad de Lima, Lima, 1995, Tomo I, p. 35. 


\section{Apostilla}

Como se aprecia de los comentarios de juristas nacionales y extranjeros que analizan y comentan con detenimiento, sapiencia y profundidad el Código civil peruano de 1984 -que hemos glosado en precedenciaellos coinciden en sus apreciaciones en cuanto resaltan su aporte personalista. Los historiadores del derecho, con la perspectiva que les otorga el tiempo, podrán destacar en el futuro que el Código civil peruano de 1984 significó el primer esfuerzo, el precursor intento, por recoger en su articulado una inspiración humanista. Verificarán en qué medida ello se cumplió. Comprobarán seguramente, que con dicho Código se dio inicio a una nueva etapa en la codificación comparada. Ello, en tanto pretendió alejarse de la filosofía individualista y patrimonialista propia del Código civil de los franceses de 1804 y de todos los códigos civiles que en él se inspiraron durante los siglos XIX y XX, para sustituirla por una concepción personalista que hace del hombre el centro y el eje del derecho. 